Article

\title{
Thermal Non-Equilibrium Heat Transfer Modeling of Hybrid Nanofluids in a Structure Composed of the Layers of Solid and Porous Media and Free Nanofluids
}

\author{
Ali J. Chamkha ${ }^{1,2}\left(\mathbb{D}\right.$, Sina Sazegar ${ }^{3}\left(\mathbb{D}\right.$, Esmael Jamesahar ${ }^{3}$ and Mohammad Ghalambaz $^{3, *(D)}$ \\ 1 Mechanical Engineering Department, Prince Mohammad Bin Fahd University, Al-Khobar 31952, \\ Saudi Arabia; achamkha@pmu.edu.sa \\ 2 RAK Research and Innovation Center, American University of Ras Al Khaimah, P.O. Box 10021, \\ Ras Al Khaimah, UAE \\ 3 Department of Mechanical Engineering, Dezful Branch, Islamic Azad University, Dezful, Iran; \\ sinasazgara@gmail.com (S.S.); behravan.jam@gmail.com (E.J.) \\ * Correspondence: m.ghalambaz@gmail.com or m.ghalambaz@iaud.ac.ir; Tel.: +98-9166442671
}

Received: 29 December 2018; Accepted: 30 January 2019; Published: 9 February 2019

\begin{abstract}
The free convection heat transfer of hybrid nanofluids in a cavity space composed of a clear flow, porous medium and a solid part is addressed. The cavity is heated from the bottom and cooled from the top. The side walls are well insulated. The upper part of the cavity is a clear space with no porous or solid materials and is filled with hybrid nanofluid. The bottom part is divided into two parts of a porous space saturated with the hybrid nanofluid and a solid thermal conductive block. There are conjugate heat transfer mechanisms between the solid block and the porous medium filled with the hybrid nanofluid as well as the hybrid nanofluid in the clear space. For the porous medium model, the local thermal non-equilibrium effects are considered. The hybrid nanofluids contain copper $(20 \mathrm{~nm})$ and alumina nanoparticles $(40 \mathrm{~nm})$ hybrid nanoparticles. The governing equations for the flow and heat transfer of the hybrid nanofluid in the clear space and the porous medium are introduced. Considering the conjugate heat transfer between the solid block and the hybrid nanofluid fluid in the pores and the porous matrix, appropriate boundary conditions for heat channeling are utilized. The governing equations are transformed into non-dimensional form to generalize the model. The finite element method is employed to solve the equations. The grid check and validation procedure are performed. Subsequently streamlines, isotherms, and Nusselt number are studied as important aspects of flow and heat transfer in the cavity. The increase in the portion of the clear flow part in the cavity enhances heat transfer due to better hybrid nanofluid circulation.
\end{abstract}

Keywords: natural convection heat transfer; hybrid nanofluid; porous medium; conjugate heat transfer

\section{Introduction}

Heat transfer from a cavity has been investigated in many engineering sciences due to its various applications. Some of these applications include building insulation, electrical appliances, cooling and designing heat exchangers and HVAC.

The interaction of convection and conduction heat transfer in a cavity in which the fluid and solid phases are in close contact is referred to as the conjugate convection heat transfer [1]. Vahl Davis [2], Turan et al. [3], Deng and Tang [4], and Sathiyamoorthy and Chamkha [5] have examined the natural convection heat transfer in a closed square cavity. They found that heat transfer is under the strong influence of the Rayleigh number. 
Nanofluids are stable suspensions of nanoparticles and a base fluid. Nanofluids have shown enhanced heat transfer properties, and various aspects of heat transfer in nanofluids have been explored in excellent reviews by Devendiran and Amirtham [6], Kumar et al. [7] and Verma and Tiwari [8]. Hybrid nanofluids are a new type of nanofluids which consist of two types of nanoparticles stably dispersed in the base fluid. The nanoparticles in the base fluid shape composite nanoparticles. Hybrid nanofluids enjoy the advantages of two types of nanoparticles. Considering hybrid nanofluids, Sarkar et al. [9], Sundar et al. [10], and Sidik [11] have presented excellent reviews on the thermophysical properties and applications of hybrid nanofluids.

Heat transfer in porous media has been the subject of many recent studies, and various aspects of heat transfer in porous media have been explored in the literature. There are many cases in which a porous medium can be treated as a local thermal equilibrium. In such a model, there are no temperature differences between the porous matrix and the fluid inside the pores. This assumption is true for media with small porosities such as geothermal reservoirs and thermal insulators. However, if the porous matrix and the fluid do not have the same temperature for any reason such as heat generation in the porous matrix, the porous medium and the fluid should be treated as the thermal non-equilibrium. The thermal equilibrium cannot be assumed for the porous media with materials of the metallic porous matrix with very high thermal conductivity or media in which heat is generated in one of the solid or fluid phases.

Most of the previous studies have addressed flow and heat transfer in porous media by considering the thermal equilibrium model. Baytas et al. [12] studied the free convection in a porous cavity. They focused on the role of the thermal conductivity of horizontal walls in heat transfer and fluid flow. The results reported by Baytas et al. indicated that the temperature of the fluid-horizontal wall interface decreases with the increase in the thermal conductivity. Baytas et al. [13] examined the free convection heat transfer in a typical cavity containing heat-generating fluid. They found that the height of the step at the interface induces a significant effect on the flow field and heat and mass transfer from the left-hand to the right-hand walls. Additionally, in certain cases, the results obtained by these authors were very well in line with the results obtained by other researchers. Wei et al. [14] investigated the solid-liquid phase change heat transfer in the presence of convection heat transfer in a porous medium using a lattice Boltzmann model. The results showed that the temperature and heat flux continuity conditions at the interface between phases of different thermos-physical properties were inherently satisfied for the model. Chen [15] investigated the lattice Boltzmann model for heat transfer in the porous media. The purpose of this study was to provide a new numerical solution to remedy the shortcomings of previous models. Gao et al. [16] investigated the modified lattice Boltzmann model for conjugate heat transfer in porous media. The numerical results of Gao et al. [16] were in a very good agreement with the analytical and numerical solutions reported in previous studies. The authors argued that the proposed model can be used as a feasible tool for conjugate heat transfer problems in porous media. Miroshnichenko et al. [17] modeled the flow and heat transfer of alumina nanofluids in a cavity composed of two layers of porous media and two layers of clear flows. The outcomes indicated that the thickness of the porous layers and clear layers plays an important role in enhancing heat transfer in the cavity. Dogonchi et al. [18] investigated the MHD natural convection of $\mathrm{Cu}$-water nanofluid in a gap between hot rectangular-cylinder and a cold circular-cylinder filled with porous medium.

Ghalambaz et al. [19] studied the natural convective heat and mass transfer of nanofluid over a vertical plate embedded in a Darcy porous medium that was exposed to the hot surface and the flux of nanoparticles. They found that the rise of the Eckert number (viscous dissipation effects) decreases the Nusselt number at the hot wall. Kasaeia et al. [20] conducted a study entitled "Nanofluid flow and heat transfer in porous media", where they comprehensively reviewed the simultaneous application of nanofluids and porous media for such purposes as heat transfer enhancement in thermal systems with different structures, flow regimes, and boundary conditions. 
There are recent studies into the Local Thermal Non-Equilibrium (LTNE) model of heat transfer in a cavity. Izadi et al. [21], Sheremet et al. [22] as well as Zargartalebi et al. [23] studied the natural convection of nanofluids in enclosures. Izadi et al. [24] also studied the MHD flow of CuO-water nanofluid in an enclosure by considering a geothermal viscosity model. The outcomes revealed that a raise in the viscosity-parameters results in the improvement of the heat transfer and convective flow intensification. Hashemi et al. [25] investigated the effect of using micropolar nanofluids in a porous medium cavity.

Considering the conjugate natural convection heat transfer and LTNE porous medium, there is a bifurcation heat flux channel at the interfacial layer. A portion of the conjugate heat flux enters the porous matrix and another portion enters the fluid inside the porous pores. Therefore, the study of conjugate natural convection heat transfer in enclosures is a very interesting heat transfer phenomenon which demands future investigation.

Very recently, Mehryan et al. [26] and Zargartalebi et al. [27] have addressed the conjugate natural convection of nanofluids in a cavity considering a LTNE model of porous medial for the case of nanofluids with only one type of nanoparticles. The present study aims to LTNE heat transfer of hybrid nanofluids which consist two type of nanoparticles. The review of the literature shows that the results of the present study are new and have not been addressed yet. The present research tends to answers the following fundamental questions regarding the natural convection flow and heat transfer of hybrid nanofluids:

(1) Does using hybrid nanofluids enhance free convection in a cavity?

(2) What are the effects of using porous space and solid blocks on the performance of hybrid nanofluids?

(3) How do the volume fraction of hybrid nanoparticles and the buoyancy effects (Rayleigh number) change the thermal performance of hybrid nanofluids?

\section{Mathematica Model}

Consider a square cavity partially filled with three regions of clear flow filled with a hybrid nanofluid, a porous medium saturated with the hybrid nanofluid and a thermal conductive solid block. Figure 1 shows a schematic view of the physical model and the coordinate system.

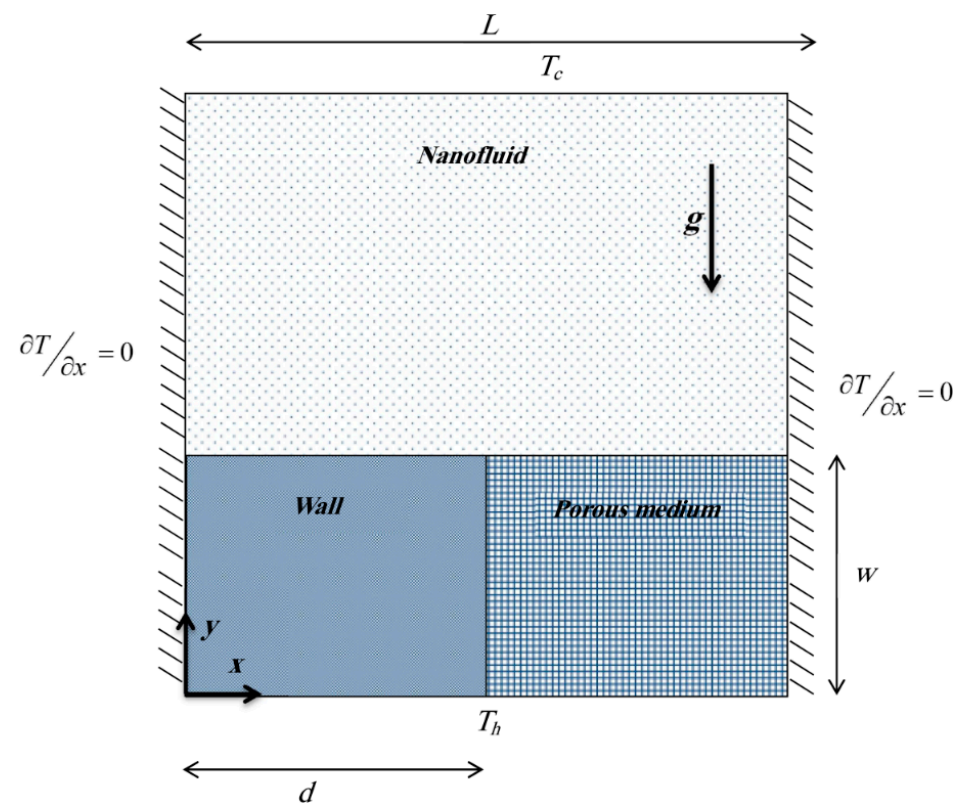

Figure 1. Schematic diagram of the physical model. 
According to the figure, the cavity is a two-dimensional square with sides of length $L$. The bottom and top horizontal walls of the closed cavity have been kept at hot temperature $T_{h}$ and the cold temperature $T_{c}$, respectively with $T_{h}>T_{c}$. In addition, the left and right vertical walls of the cavity are insulated. The height of the porous region and the solid block is $w$ while the length of the solid block is $d$. The hybrid nanofluid is under the influence of the gravitational acceleration $g$ which acts in the opposite direction of the vertical axis (y). It is also assumed that the hybrid nanofluid is Newtonian and incompressible. The flow is laminar in the clear region, and Darcy-Brinkman model is applied for the porous domain region. The buoyancy effects are modeled using the Boussinesq approximation. It is assumed that the surface of porous structure is treated using charges techniques or other methods in a way that the nanoparticles cannot deposit at the solid surface.

\subsection{The Governing Equations for the Nanofluid}

The governing equations for the fluid phase include the continuity equation, the equations of momentum in the horizontal direction, momentum in the vertical direction, and energy. The flow function is also added to these equations, so, for the fluid, we will have:

$$
\begin{gathered}
\frac{\partial u}{\partial x}+\frac{\partial v}{\partial y}=0 \\
\rho_{h n f}\left(u \frac{\partial u}{\partial x}+v \frac{\partial u}{\partial y}\right)=-\frac{\partial p}{\partial x}+\mu_{h n f}\left(\frac{\partial^{2} u}{\partial x^{2}}+\frac{\partial^{2} u}{\partial y^{2}}\right) \\
\rho_{h n f}\left(u \frac{\partial v}{\partial x}+v \frac{\partial v}{\partial y}\right)=-\frac{\partial p}{\partial y}+\mu_{h n f}\left(\frac{\partial^{2} v}{\partial x^{2}}+\frac{\partial^{2} v}{\partial y^{2}}\right)+\rho_{h n f} g \\
u \frac{\partial T_{h n f}}{\partial x}+v \frac{\partial T_{h n f}}{\partial y}=\frac{k_{h n f}}{\left(\rho c_{p}\right)_{h n f}}\left(\frac{\partial^{2} T_{h n f}}{\partial x^{2}}+\frac{\partial^{2} T_{h n f}}{\partial y^{2}}\right)
\end{gathered}
$$

where $u$ is the horizontal component of the fluid velocity, $v$ is the vertical component of the fluid velocity, $x$ and $y$ are the vertical and horizontal components of the location, respectively, $\rho_{h n f}$ is the nanofluid density, $g$ is the gravitational acceleration and $p$ is pressure. In addition, $T_{h n f}$ is the nanofluid temperature, $\mu_{h n f}$ is the dynamic viscosity, $k_{h n f}$ is the thermal conductivity of the nanofluid, $c_{p h n f}$ is the thermal capacity of the nanofluid.

\subsection{Governing Equations for the Porous Medium}

According to the problem definition, the cavity containes a porous medium. This necessitates the definition of equations related to the porous medium. For this purpose, the continuity equation, the equations of momentum in the horizontal direction, momentum in the vertical direction, the fluid energy, and the solid energy in the porous medium will be as follows:

$$
\begin{gathered}
\frac{\partial u}{\partial x}+\frac{\partial v}{\partial y}=0 \\
\frac{\rho_{h n f}}{\varepsilon^{2}}\left(u \frac{\partial u}{\partial x}+v \frac{\partial u}{\partial y}\right)=-\frac{\partial p}{\partial x}+\frac{\mu_{h n f}}{\varepsilon}\left(\frac{\partial^{2} u}{\partial x^{2}}+\frac{\partial^{2} u}{\partial y^{2}}\right)-\frac{\mu_{h n f}}{K} u \\
\frac{\rho_{h n f}}{\varepsilon^{2}}\left(u \frac{\partial v}{\partial x}+v \frac{\partial v}{\partial y}\right)=-\frac{\partial p}{\partial y}+\frac{\mu_{h n f}}{\varepsilon}\left(\frac{\partial^{2} v}{\partial x^{2}}+\frac{\partial^{2} v}{\partial y^{2}}\right)-\frac{\mu_{h n f}}{K} v+\rho_{h n f} g \\
\frac{1}{\varepsilon}\left(u \frac{\partial T_{h n f}}{\partial x}+v \frac{\partial T_{h n f}}{\partial y}\right)=\frac{k_{h n f}}{\left(\rho c_{p}\right)_{h n f}}\left(\frac{\partial^{2} T_{h n f}}{\partial x^{2}}+\frac{\partial^{2} T_{h n f}}{\partial y^{2}}\right)+\frac{h_{h n f s}\left(T_{s}-T_{h n f}\right)}{\varepsilon(\rho c)_{h n f}}
\end{gathered}
$$




$$
0=\frac{k_{s}}{(\rho c)_{s}}\left(\frac{\partial^{2} T_{s}}{\partial x^{2}}+\frac{\partial^{2} T_{s}}{\partial y^{2}}\right)+\frac{h_{h n f s}}{(1-\varepsilon)(\rho c)_{s}}\left(T_{h n f}-T_{s}\right)
$$

where $T_{S}$ is the solid medium temperature in the porous medium and $\varepsilon$ is the porosity coefficient. In addition, the flow stream function for the clear fluid and the fluid inside the porous medium can be defined as follows:

$$
\left(\frac{\partial u}{\partial y}-\frac{\partial v}{\partial x}\right)=\nabla^{2} \psi
$$

where $\Psi$ is the nanofluid flow function.

\subsection{Governing Equations for the Solid Medium}

As already mentioned, the hot wall is thick and will be considered as a solid medium. For this purpose, the given medium will only include an energy equation. Therefore, we will have:

$$
\left(\frac{\partial^{2} T_{w}}{\partial x^{2}}+\frac{\partial^{2} T_{w}}{\partial y^{2}}\right)=0
$$

where $T_{w}$ is the temperature in the solid medium, $x$ and $y$ are the horizontal and vertical components of the location, respectively.

\subsection{Boundary Conditions}

\subsubsection{The Bounded Walls of the Cavity}

The $u$ and $v$ velocities on solid walls:

$$
\begin{gathered}
u=v=0 \\
T(x, 0)=T_{h}, T(x, L)=T_{c},\left.\frac{\partial T}{\partial x}\right|_{(y, \mathrm{~L})}=0,\left.\frac{\partial T}{\partial x}\right|_{(y, 0)}=0
\end{gathered}
$$

where $T$ is the temperature, $u$ is the horizontal component of velocity, $v$ is the vertical component of the velocity, $x$ and $y$ are respectively the horizontal and vertical components of the location, and $L$ is the cavity length.

\subsubsection{The Porous Medium and Clear Flow Interface}

The boundary condition of porous-clear flow has been studied in [28,29]. In the present study, the continuity of velocity and tension at the interface is considered. In addition, assuming that the heat transfer between the fluid/nanofluid and the porous medium matrix is large enough, the temperature is assumed to be equal at the interface between the fluid/nanofluid and the porous medium matrix. Therefore, the boundary conditions are the interface of the porous and nanofluid introduced as:

$$
\begin{gathered}
u_{h n f}=u_{\text {porous }}, v_{\text {hnf }}=v_{\text {porous }}, \\
\left.\mu_{h n f} \frac{\partial u}{\partial n}\right|_{h n f}=\left.\mu_{h n f, e f f} \frac{\partial u}{\partial n}\right|_{\text {porous }},\left.\mu_{h n f} \frac{\partial v}{\partial n}\right|_{h n f}=\left.\mu_{h n f, e f f} \frac{\partial v}{\partial n}\right|_{\text {porous }} \\
\left.T_{h n f}\right|_{h n f}=\left.T_{h n f}\right|_{\text {porous }}=\left.T_{s}\right|_{\text {porous }} \\
\left.k_{\text {hnf }} \frac{\partial T_{f / h n f}}{\partial n}\right|_{h n f}=\left.k_{h n f, e f f} \frac{\partial T_{h n f}}{\partial n}\right|_{\text {porous }}+\left.k_{s, e f f} \frac{\partial T_{s}}{\partial n}\right|_{\text {porous }}=q^{\prime \prime}{ }_{i}
\end{gathered}
$$

where $k_{h n f, e f f}=\varepsilon \times k_{h n f}$ and $k_{s, \text { eff }}=(1-\varepsilon) k_{s}$ and $\mu_{h n f, e f f}=\mu_{h n f} / \varepsilon$. 


\subsubsection{The Porous Medium and Solid Block}

Introducing a proper boundary condition at the interface between the porous medium and the solid conductive wall has been a challenging issue. This type of boundary condition for porous-solid wall interface has been previously discussed in some excellent works [30-33]. In the present study the non-slip and non-penetration conditions are established for the velocity at the interface between the porous medium and the solid medium. Considering the continuity of temperature and energy balance at the interface, the thermal boundary conditions at the interface of the porous medium and solid wall are introduced as:

$$
\begin{gathered}
\left.T_{w}\right|_{\text {wall }}=\left.T_{\text {hnf }}\right|_{\text {porous }}=\left.T_{s}\right|_{\text {porous }} \\
\left.k_{w} \frac{\partial T_{w}}{\partial n}\right|_{\text {wall }}=\left.k_{\text {hnf,eff }} \frac{\partial T_{\text {hnf }}}{\partial n}\right|_{\text {porous }}+\left.k_{s, e f f} \frac{\partial T_{s}}{\partial n}\right|_{\text {porous }}=q^{\prime \prime}{ }_{i}
\end{gathered}
$$

where $k_{w}$ is the thermal conductivity of the wall and $T_{w}$ is the temperature of the wall.

\subsubsection{The Clear Flow and Solid Block}

The no-slip and no permeability of solid wall are adopted for the fluid flow. The continuity of temperature and heat is used for the thermal boundary condition as:

$$
\begin{gathered}
\left.T_{w}\right|_{\text {wall }}=\left.T_{\text {hnf }}\right|_{\text {porous }}=\left.T_{s}\right|_{\text {porous }} \\
\left.k_{w} \frac{\partial T_{w}}{\partial x}\right|_{\text {wall }}=\left.k_{\text {hnf }} \frac{\partial T_{\text {hnf }}}{\partial x}\right|_{\text {hnf }}
\end{gathered}
$$

\subsection{Thermophysical Properties}

Here, several models of thermal conductivity and dynamic viscosity of nanofluids are utilized and the results are plotted in Figure 2.

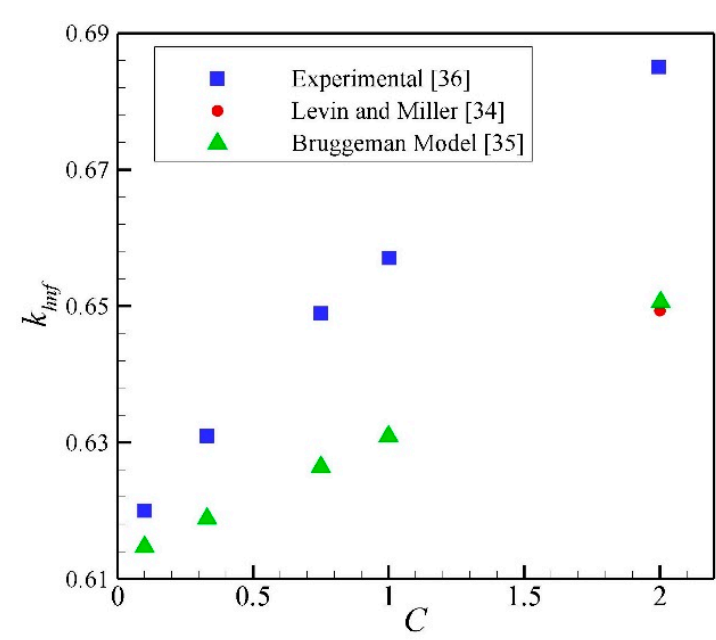

(a)

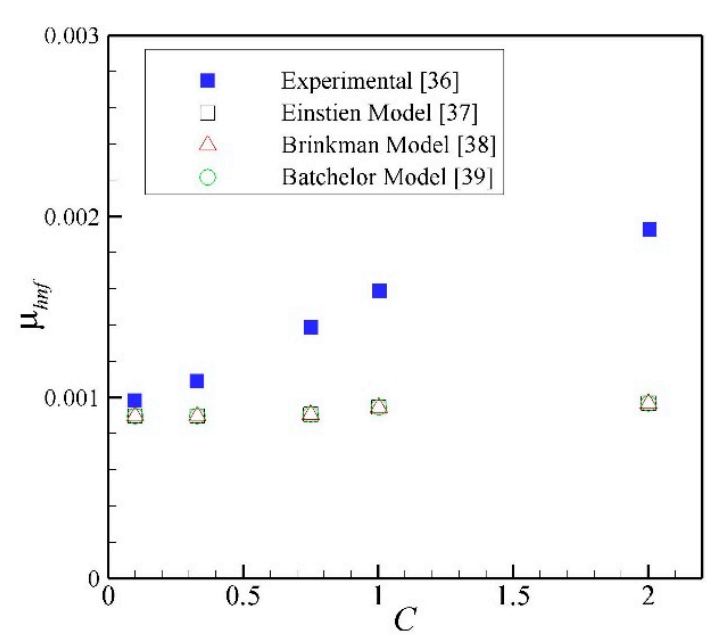

(b)

Figure 2. Comparison of the theoretical and experimental results; (a) thermal conductivity of $\mathrm{Al}_{2} \mathrm{O}_{3}-\mathrm{Cu}$ /water hybrid nanofluid, (b) Dynamic viscosity of $\mathrm{Al}_{2} \mathrm{O}_{3}-\mathrm{Cu}$ / water hybrid nanofluid.

The Levin and Miller [34] and Bruggman [35] models are adopted for the prediction of thermal conductivity of the $\mathrm{Al}_{2} \mathrm{O}_{3}-\mathrm{Cu} /$ water hybrid nanofluid and the results are presented in Figure 2a. The experimental data in [36] have been used as a comparison reference. Considering the dynamic viscosity, the Einstein model [37], Brinkman model [38] and Batchelor model [39] are utilized for the prediction of dynamic viscosity. The experimental results in [36] have also been utilized as a reference 
comparison. As can be seen, the dynamic viscosity and thermal conductivity of the hybrid nanofluid cannot be predicted properly using the available models. Hence, the experimental data in [36] have been directly utilized for the convection heat transfer analysis of the present study. The experimental results in [36] for dynamic viscosity and thermal conductivity are summarized in Table 1. The hybrid nanofluid sample in [36] was obtained using the hydrogen-reduction technique from a powder mixture containing $90 \%$ of alumina and $10 \%$ of copper oxide. Based on [36], using ultrasonic and a two-step synthesis method, a stable and uniform suspension of hybrid nanofluids of $\mathrm{Al}_{2} \mathrm{O}_{3} / \mathrm{Cu}$ water with $0.1-2 \%$ volume fraction of nanoparticles was prepared. The thermal conductivity of the nanofluid in the present study is directly extracted from Table 1.

Table 1. Thermal conductivity and dynamic viscosity used for $\mathrm{Al}_{2} \mathrm{O}_{3}-\mathrm{Cu}$ /water [36].

\begin{tabular}{ccccc}
\hline$C_{\text {hnp }}(\mathbf{\%})$ & $\boldsymbol{C}_{\boldsymbol{C u}}(\mathbf{\%})$ & $\boldsymbol{C}_{\text {Al2O3 }}(\%)$ & $\boldsymbol{k}_{\text {hnf }}(\mathrm{W} / \mathbf{m} \cdot \mathbf{K})$ & $\boldsymbol{\mu}_{\text {hnf }}(\mathbf{k g} / \mathbf{m} \cdot \mathbf{s})$ \\
\hline 0.1 & 0.0038 & 0.0962 & 0.61988 & 0.000916 \\
0.33 & 0.0125 & 0.3175 & 0.63098 & 0.001098 \\
0.75 & 0.0285 & 0.1615 & 0.649004 & 0.001386 \\
1 & 0.038 & 0.962 & 0.657008 & 0.001602 \\
2 & 0.0759 & 0.9241 & 0.684992 & 0.001953 \\
\hline
\end{tabular}

The density and thermal capacity of the hybrid nanofluid are evaluated using the following equations [40]:

$$
\begin{gathered}
\rho_{h n f}=C_{A l 2 \mathrm{O} 3} \rho_{A l 2 \mathrm{O} 3}+C_{C u} \rho_{C u}+\left(1-C_{h n f}\right) \rho_{f} \\
\left(\rho C_{p}\right)_{h n f}=C_{A l 2 \mathrm{O} 3}\left(\rho C_{p}\right)_{A l 2 \mathrm{O} 3}+C_{C u}\left(\rho C_{p}\right)_{C u}+\left(1-C_{h n f}\right)\left(\rho C_{p}\right)_{f}
\end{gathered}
$$

The thermal expansion of the hybrid nanofluid is evaluated using:

$$
\beta_{\text {hnf }}=C_{\mathrm{Al2O} 3} \beta_{\mathrm{Al2O} 3}+C_{\mathrm{Cu}} \beta_{\mathrm{Cu}}+\left(1-C_{h n f}\right) \beta_{f}
$$

Finally, the effective thermal conductivity of the porous medium and the liquid inside the pores can be obtained according to the method described in [41].

\subsection{Non-Dimensional form of Governing Equations}

Here, the base fluid thermophysical properties are utilized to transform the governing equations into a general non-dimensional form. In order to achieve the non-dimensional form of the equations, the following form of the non-dimensional parameters is adopted:

$$
\begin{gathered}
X=\frac{x}{L}, Y=\frac{y}{L}, D=\frac{d}{L}, W=\frac{w}{L}, U=\frac{u L}{\alpha_{f}}, V=\frac{v L}{\alpha_{f}}, \Psi=\frac{\psi}{\alpha_{f}}, \\
P=\frac{p L^{2}}{\rho_{f} \alpha_{f}^{2}}, D a=\frac{k}{L^{2}}, \operatorname{Pr}=\frac{v_{f}}{\alpha_{f}}, R a=\frac{g \beta \Delta T L^{3}}{v_{f} \alpha_{f}}, \\
\theta_{h n f}=\frac{\left(T_{h n f}-T_{c}\right)}{\Delta T}, \theta_{s}=\frac{\left(T_{s}-T_{c}\right)}{\Delta T}, \theta_{w}=\frac{\left(T_{w}-T_{c}\right)}{\Delta T}, \\
H=\frac{h_{h n f} L^{2}}{k_{h n f}}, k_{r}=\frac{k_{h n f}}{(1-\varepsilon) k_{s}}, R_{k}=\frac{k_{w}}{k_{f}},
\end{gathered}
$$

where $X, Y, D, W, U, V, \Psi, P, \theta$ are respectively the non-dimensional expression of the horizontal position of location, the vertical position of location, the non-dimensional width of the solid medium, the non-dimensional width of the porous medium, the velocity component along $x$ direction, the velocity component along $y$ direction, the flow, pressure, and temperature functions. $\theta_{\text {hnf }}$ is the non-dimensional temperature of hybrid nanofluid, $\theta s$ is the non-dimensional temperature of porous matrix, and $\theta_{w}$ is the non-dimensional temperature of wall. In addition, $D a, \operatorname{Pr}, R a$ are Darcy, Prandtl, 
and Rayleigh numbers. $H, k_{r}$, and $R_{k}$ are also the permeability coefficient of the porous medium, the conductivity ratio coefficient of the porous material and the thermal conductivity ratio of wall-to-fluid. On the other hand, $\Delta T$ is the temperature difference between the hot and cold walls, which is defined as $\Delta T=T_{h}-T_{c}$. Now, by involving Equation (20) the governing Equations of (1) to (11) are transformed in to the following non-dimensional form.

\subsubsection{Clear Flow}

$$
\begin{gathered}
\frac{\partial U}{\partial X}+\frac{\partial V}{\partial Y}=0 \\
U \frac{\partial U}{\partial X}+V \frac{\partial U}{\partial Y}=-\frac{\rho_{f}}{\rho_{h n f}} \frac{\partial P}{\partial X}+\left(\frac{\rho_{f}}{\rho_{h n f}}\right)\left(\frac{\mu_{h n f}}{\mu_{f}}\right) \operatorname{Pr}\left(\frac{\partial^{2} U}{\partial X^{2}}+\frac{\partial^{2} U}{\partial Y^{2}}\right), \\
U \frac{\partial V}{\partial X}+V \frac{\partial V}{\partial Y}=-\frac{\rho_{f}}{\rho_{h n f}} \frac{\partial P}{\partial Y}+\left(\frac{\rho_{f}}{\rho_{h n f}}\right)\left(\frac{\mu_{h n f}}{\mu_{f}}\right) \operatorname{Pr}\left(\frac{\partial^{2} V}{\partial X^{2}}+\frac{\partial^{2} V}{\partial Y^{2}}\right)+\frac{(\rho \beta)_{h n f}}{\rho_{h n f} \beta_{f}} \operatorname{Pr} \cdot R a \cdot \theta, \\
U \frac{\partial \theta_{h n f}}{\partial X}+V \frac{\partial \theta_{h n f}}{\partial Y}=\frac{\alpha_{h n f}}{\alpha_{f}}\left(\frac{\partial^{2} \theta_{h n f}}{\partial X^{2}}+\frac{\partial^{2} \theta_{h n f}}{\partial Y^{2}}\right)
\end{gathered}
$$

The non-dimensional stream function was also obtained using:

$$
\frac{\partial U}{\partial Y}-\frac{\partial V}{\partial X}=\nabla^{2} \Psi,
$$

where the ratio of the effective thermal diffusivity of nanofluid to that of the base fluid is defined as:

$$
\alpha_{r}=\frac{\alpha_{h n f}}{\alpha_{f}}=\frac{k_{h n f}}{k_{f}} \frac{\left(\rho c_{p}\right)_{f}}{\left(\rho c_{p}\right)_{h n f}},
$$

\subsubsection{Porous Medium Layer}

$$
\begin{gathered}
\frac{\partial U}{\partial X}+\frac{\partial V}{\partial Y}=0, \\
\frac{1}{\varepsilon^{2}} \frac{\partial U}{\partial \tau}+\frac{1}{\varepsilon^{2}}\left(U \frac{\partial U}{\partial X}+V \frac{\partial U}{\partial Y}\right)=-\left(\frac{\rho_{f}}{\rho_{h n f}}\right) \frac{\partial P}{\partial X}+\frac{1}{\varepsilon}\left(\frac{\rho_{f}}{\rho_{h n f}}\right)\left(\frac{\mu_{h n f}}{\mu_{f}}\right) \operatorname{Pr}\left(\frac{\partial^{2} U}{\partial X^{2}}+\frac{\partial^{2} U}{\partial Y^{2}}\right) \\
+\left(\frac{\rho_{f}}{\rho_{h n f}}\right)\left(\frac{\mu_{h n f}}{\mu_{f}}\right) \frac{\operatorname{Pr}}{D a} U \\
\frac{1}{\varepsilon^{2}} \frac{\partial V}{\partial \tau}+\frac{1}{\varepsilon^{2}}\left(U \frac{\partial V}{\partial X}+V \frac{\partial V}{\partial Y}\right)=-\left(\frac{\rho_{f}}{\rho_{h n f}}\right) \frac{\partial P}{\partial Y}+\frac{1}{\varepsilon}\left(\frac{\rho_{f}}{\rho_{h n f}}\right)\left(\frac{\mu_{h n f}}{\mu_{f}}\right) \operatorname{Pr}\left(\frac{\partial^{2} V}{\partial X^{2}}+\frac{\partial^{2} V}{\partial Y^{2}}\right) \\
+\left(\frac{\rho_{f}}{\rho_{h n f}}\right)\left(\frac{\mu_{h n f}}{\mu_{f}}\right) \frac{\operatorname{Pr}}{D a} V+\frac{(\rho \beta)_{h n f}}{\rho_{h n f} \beta_{f}} \operatorname{Pr} \cdot R a \cdot \theta \\
\frac{1}{\varepsilon} \frac{\partial \theta_{h n f}}{\partial \tau}+\frac{1}{\varepsilon}\left(U \frac{\partial \theta_{h n f}}{\partial X}+V \frac{\partial \theta_{h n f}}{\partial Y}\right)=\frac{\alpha_{h n f}}{\alpha_{f}}\left(\frac{\partial^{2} \theta_{h n f}}{\partial X^{2}}+\frac{\partial^{2} \theta_{h n f}}{\partial Y^{2}}\right)+H\left(\theta_{s}-\theta_{f}\right), \\
0=\left(\frac{\partial^{2} \theta_{s}}{\partial X^{2}}+\frac{\partial^{2} \theta_{s}}{\partial Y^{2}}\right)+H\left(\theta_{h n f}-\theta_{s}\right), \\
\frac{\partial U}{\partial Y}-\frac{\partial V}{\partial X}=\nabla^{2} \Psi,
\end{gathered}
$$


2.6.3. Solid Block

$$
\frac{\partial^{2} \theta_{w}}{\partial X^{2}}+\frac{\partial^{2} \theta_{w}}{\partial Y^{2}}=0
$$

\subsection{The Non-Dimensional Boundary Conditions}

The boundary conditions corresponding to the introduced governing equations are transformed into the non-dimensional form using the non-dimensional parameters and variables of Equation (20).

2.7.1. The Bounded Walls of the Cavity

The $U$ and $V$ velocities on solid walls:

$$
\begin{gathered}
U=V=0 \\
\theta(\mathrm{X}, 0)=1, \theta(\mathrm{X}, \mathrm{L})=0,\left.\frac{\partial \theta}{\partial X}\right|_{(\mathrm{Y}, \mathrm{L})}=0,\left.\frac{\partial \theta}{\partial X}\right|_{(\mathrm{Y}, 0)}=0 .
\end{gathered}
$$

2.7.2. The Porous Medium and Clear Flow Interface

$$
\begin{gathered}
U_{h n f}=U_{\text {porous }}, V_{h n f}=V_{\text {porous }} \\
\left.\frac{\partial U}{\partial n}\right|_{h n f}=\left.\frac{1}{\varepsilon} \frac{\partial U}{\partial n}\right|_{\text {porous }},\left.\frac{\partial V}{\partial n}\right|_{h n f}=\left.\frac{1}{\varepsilon} \frac{\partial V}{\partial n}\right|_{\text {porous }} \\
\left.\theta_{f}\right|_{h n f}=\left.\theta_{f}\right|_{\text {porous }}=\left.\theta_{s}\right|_{\text {porous }} \\
\left.\frac{\partial \theta_{h n f}}{\partial n}\right|_{h n f}=\left.\varepsilon \frac{\partial \theta_{h n f}}{\partial n}\right|_{\text {porous }}+\left.K_{r}^{-1} \frac{\partial \theta_{\text {hnf }}}{\partial n}\right|_{\text {porous }}=Q_{i}
\end{gathered}
$$

2.7.3. The Porous Medium and Solid Block

$$
\begin{gathered}
\left.\theta_{w}\right|_{\text {wall }}=\left.\theta_{\text {hnf }}\right|_{\text {porous }}=\left.\theta_{s}\right|_{\text {porous }} \\
\left.R_{k} \frac{\partial \theta_{w}}{\partial n}\right|_{\text {wall }}=\left.\varepsilon \frac{\partial \theta_{h n f}}{\partial n}\right|_{\text {porous }}+\left.K_{r}^{-1} \frac{\partial \theta_{S}}{\partial n}\right|_{\text {porous }}=Q_{i}
\end{gathered}
$$

\subsection{Nusselt Number}

The important characteristic parameter of the present study for analysis of heat transfer is the Nusselt number. The Nusselt number is generally defined as follows:

$$
N u=\frac{h L}{k}
$$

where $h$ is the convection heat transfer coefficient, $L$ is the cavity length, and $k$ is the thermal conductivity. Now, using the non-dimensional parameters of Equation (20) and substituting them into Equation (38), and after the simplification, the non-dimensional equation of the Nusselt number is obtained as:

$$
N u_{\text {Local }}=-\frac{\partial \theta}{\partial n}
$$

To calculate the Nusselt number in the cavity, according to the schematic Figure 1, the Equation (40) is integrated on the hot wall, so we will have:

$$
N u=-\int_{0}^{1} \frac{\partial \theta}{\partial X} d Y
$$


However, it should be noted that the problem has been considered assuming the thermal non-equilibrium for the porous medium. Therefore, defining $\theta_{f}$ and $\theta_{s}$ as the non-dimensional temperature of the fluid and solid matrix respectively, the Nusselt number will be defined as follows:

The Nusselt number for fluid in the porous medium:

$$
N u_{f}=\left(-\int_{0}^{1} \frac{\partial \theta_{h n f}}{\partial X} d Y\right)_{X=D}
$$

\section{Solution Method and Validation}

The finite element method is employed to numerically solve the governing equations of Equations (21)-(24) in the clear flow, Equations (27)-(32) in the porous layer and Equation (33) in the solid block along with the boundary conditions of Equations (34)-(37). The governing equations are first written in the weak form and then numerically integrated over the mesh domain. The discretized equations are iteratively solved using the Newtown method as fully coupled equations until convergence is achieved. The relative residual lower than $10^{-7}$ is considered as a converged solution. The grid check and code verification are performed in the following sub-sections.

\section{The Solution Independence of the Computational Grid}

In order to monitor the effect of the mesh size on the accuracy of the results, the calculations are repeated for various mesh sizes. Table 2 shows the details of the utilized grids in each case. The maximum value of the hybrid nanofluid flow stream function $\left(\psi_{\max }\right)$ is monitored and reported in Figure 3 for each case defined in Table 2. The results of Figure 3 indicates that the grid size of case 4 can provide adequate accuracy with fair computational time. Hence grid of case 4 is selected as the computational grid for this study.

Table 2. The details of each case of the grids.

\begin{tabular}{cccc}
\hline Cases & Divisions & Number of Domain Nodes & Number of Boundary Nodes \\
\hline Case 1 & $20 \times 20$ & 400 & 110 \\
Case 2 & $50 \times 50$ & 2500 & 275 \\
Case 3 & $100 \times 100$ & 10,000 & 550 \\
Case 4 & $150 \times 150$ & 22,500 & 825 \\
Case 5 & $200 \times 200$ & 40,000 & 1100 \\
Case 6 & $250 \times 250$ & 62,500 & 1375 \\
Case 7 & $300 \times 300$ & 90,000 & 1650 \\
\hline
\end{tabular}

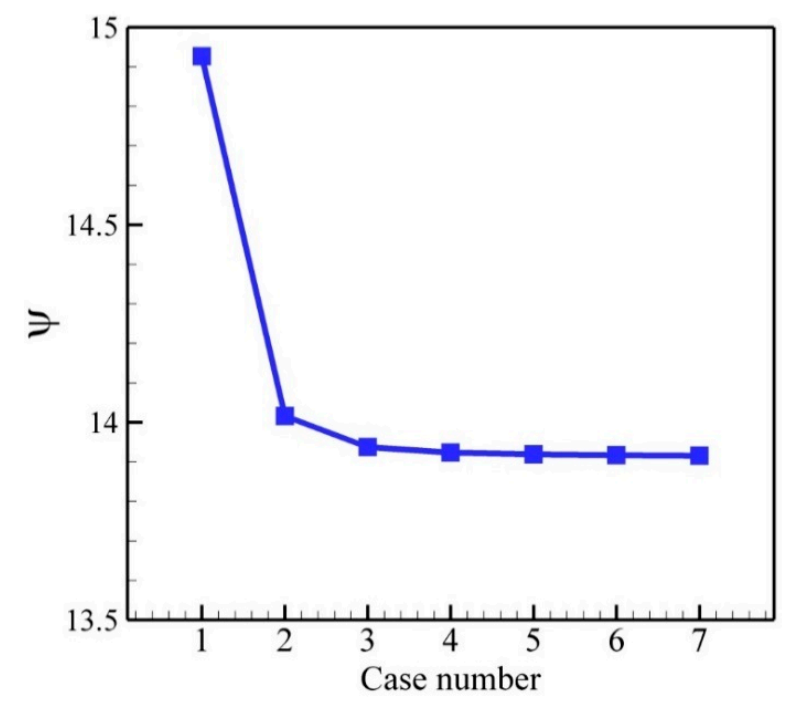

Figure 3. Changes in the amount of flow in the cavity for different sizes of the computational grid. 
Figure 4 shows the grid of case 4 . The grid is in a form of regular horizontal and vertical lines and is denser near the boundaries. The reason for this is the importance of the flow behavior and temperature gradients at the boundaries.

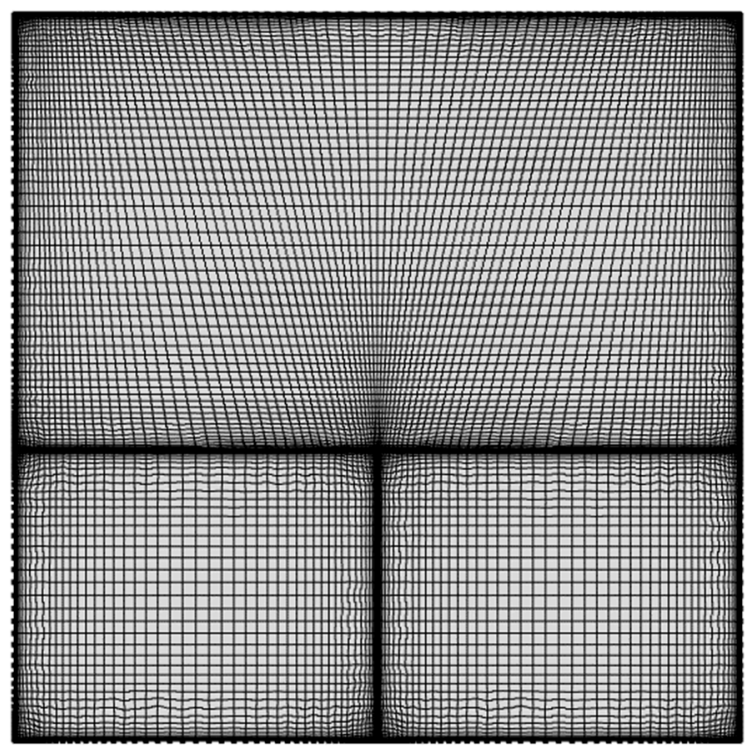

Figure 4. Computational grid \# 4 according to Table 2.

In the following, to verify the numerical solution method, the results from the present study are compared with that from the previous studies so that the accuracy or inaccuracy of the numerical solution method can be confirmed ultimately by the comparison of the results.

The average Nusselt number as a function of the nanoparticles volume fraction reported by Kahveci [42] is compared with that reported by the present study. Kahveci [42] investigated the natural heat transfer in a closed cavity filled with nanofluid. In the study, the Rayleigh number was assumed to vary from $10^{4}-10^{6}$ and the volume fraction was assumed to range from $0 \%$ to $20 \%$, and the $\mathrm{Cu}$, $\mathrm{Ag}, \mathrm{CuO}, \mathrm{Al}_{2} \mathrm{O}_{3}$, and $\mathrm{TiO}_{2}$ nanoparticles were used in the water-based nanofluid. Figure 5 shows the average Nusselt number reported by Kahveci in comparison with the present study. Kahveci [42] has used a homogeneous model to investigate the nanofluid behavior. There is a good agreement between the results from the given study and those from the present study.

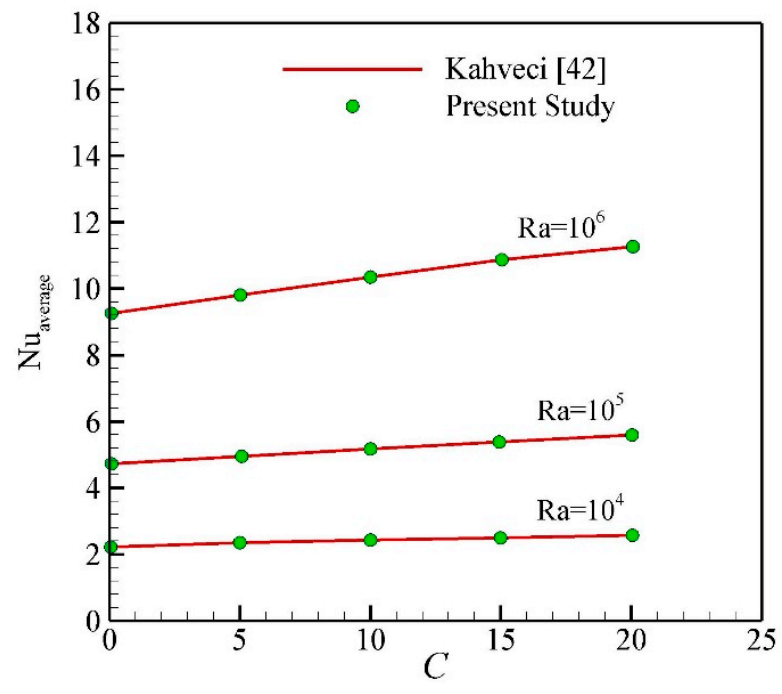

Figure 5. The comparison of the average Nusselt number as a function of the nanoparticles volume fraction reported by Kahveci [42] and the present study. 
Bourantas et al. [43] studied the natural convection heat transfer of nanofluids in a cavity filled with a porous medium. In the study, a heat source was assumed at the bottom of the cavity and other walls of the cavity were assumed to be cold. The heat source was considered as a factor of the cavity length, which was placed with the same distance from the vertical wall on its both sides. The heat source was under constant heat flux. Considering the heat flux formulation of [43], Table 3 illustrates the results presented in [43] in comparison with the results from the present study. It shows the average Nusselt number for different Darcy numbers as a function of Rayleigh number. It also demonstrates that the increase in the Rayleigh number leads to an increase in the Nusselt number and heat transfer in the cavity. On the other hand, the decreased Darcy number in high Rayleigh numbers reduces the heat transfer, while in lower Rayleigh numbers, the Darcy number does not have a significant effect on the heat transfer. A comparison of the results indicates a good agreement between the results of this study and those of the present study.

Table 3. The comparison of the average Nusselt number reported in Bourantas et al. [43] and the results obtained in the present study.

\begin{tabular}{ccccccc}
\hline \multirow{2}{*}{$\boldsymbol{a} \boldsymbol{a}$} & \multicolumn{2}{c}{$\boldsymbol{R} \boldsymbol{a}=\mathbf{1 0}^{\mathbf{4}}$} & \multicolumn{2}{c}{$\boldsymbol{R} \boldsymbol{a}=\mathbf{1 0}^{\mathbf{5}}$} & \multicolumn{2}{c}{$\boldsymbol{R a = \mathbf { 1 0 } ^ { \mathbf { 6 } }}$} \\
\cline { 2 - 7 } & {$[43]$} & Present Study & {$[43]$} & Present Study & [43] & Present Study \\
\hline $10^{-3}$ & 5.9 & 6.01 & 5.6 & 5.7 & 8.83 & 8.6 \\
$10^{-4}$ & 5.84 & 6.01 & 5.37 & 5.5 & 5.36 & 5.42 \\
$10^{-5}$ & 5.8 & 5.82 & 5.7 & 5.8 & 5.04 & 5.17 \\
\hline
\end{tabular}

Mehryan et al. [41] examined the free heat transfer of the hybrid nanofluid in a cavity filled with a porous medium. The cavity in [41] was a square in which the left and right walls were kept at the hot and cold temperatures, respectively. In addition, the horizontal walls were assumed to be insulated. The hybrid nanofluid used was $\mathrm{Al}_{2} \mathrm{O}_{3}-\mathrm{Cu}$, which was soluble in the water base fluid. To analyze the behavior of the hybrid nanofluid in the porous medium, the Darcy equation was used and the nanofluid was assumed to be homogeneous. Figure 6 presents the results reported by Mehryan et al. [41] in comparison with those from the present study. The results show that heat transfer decreases by increasing the volume fraction of nanoparticles. When the Rayleigh number increases, heat transfer decreases significantly with the increased volume fraction of nanoparticles. In Figure 6, there is a good agreement between the results reported in the given study and those from the present study.

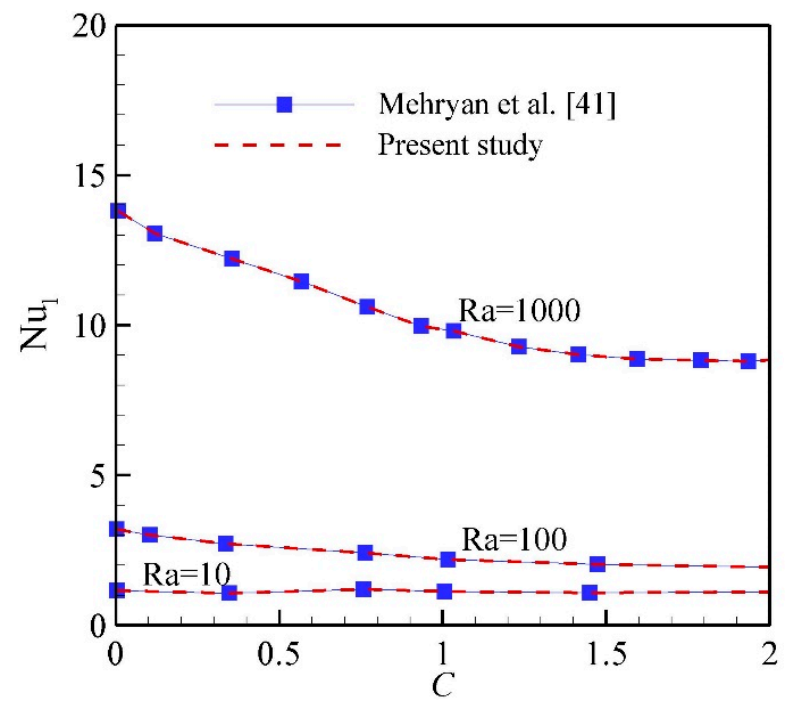

Figure 6. The comparison of the average Nusselt number reported in Mehryan et al. [41] and the results from the present study. 


\section{Results}

In the present study, two nanoparticles of $\mathrm{Al}_{2} \mathrm{O}_{3}$ and $\mathrm{Cu}$ in the base fluid of water were selected as the hybrid nanofluid. Table 4 presents the thermal and rheological properties of $\mathrm{Al}_{2} \mathrm{O}_{3}$ and $\mathrm{Cu}$ nanoparticles [36], as well as water fluid. As can be seen, the conductivity $(k)$ of $\mathrm{Cu}$ is much higher than that of $\mathrm{Al}_{2} \mathrm{O}_{3}$, and adding $\mathrm{Cu}$ can help to overcome the drawbacks of $\mathrm{Al}_{2} \mathrm{O}_{3}$ and water and obtain a hybrid nanofluid with higher conductivity. However, due to the higher density of $\mathrm{Cu}$ than $\mathrm{Al}_{2} \mathrm{O}_{3}$, the dynamic viscosity of the resulting nanofluid increases, which may have negative effects. The dynamic viscosity and thermal conductivity of the hybrid nanofluid is evaluated using the actual experimental data reported in Table 1. The data in Table 4 are used to evaluate the other thermophysical properties such as hybrid nanofluid density or heat capacity.

Table 4. The properties of the components of $\mathrm{Al}_{2} \mathrm{O}_{3}-\mathrm{Cu} /$ water nanofluid [36].

\begin{tabular}{cccc}
\hline Properties & Water & $\mathbf{C u}$ & $\mathbf{A l}_{\mathbf{2}} \mathbf{O}_{\mathbf{3}}$ \\
\hline$C_{p}(\mathrm{~J} / \mathrm{kg} \cdot \mathrm{K})$ & 4179 & 385 & 765 \\
$k(\mathrm{~W} / \mathrm{m} \cdot \mathrm{K})$ & 0.613 & 401 & 40 \\
$\alpha\left(\mathrm{m}^{2} / \mathrm{s}\right)$ & $1.47 \times 10^{-7}$ & $1.11 \times 10^{-4}$ & $13.1 \times 10^{-7}$ \\
$\beta\left(\mathrm{K}^{-1}\right)$ & $21 \times 10^{16}$ & $1.67 \times 10^{16}$ & $0.85 \times 10^{16}$ \\
$\rho\left(\mathrm{kg} / \mathrm{m}^{3}\right)$ & $997 / 1$ & 8933 & 3970 \\
$\mu(\mathrm{kg} / \mathrm{m} \cdot \mathrm{s})$ & $8.9 \times 10^{-4}$ & - & - \\
\hline
\end{tabular}

The default value of the non-dimensional parameters is adopted as $\operatorname{Ra}=10^{6}, \operatorname{Pr}=5, C=1, D a=10^{3}$, $H=10, K r=10, R_{k}=10, D=0.5, W=0.4, \varepsilon=0.3$ and the results of the present study are reported for these non-dimensional parameters otherwise the value will be stated.

\subsection{The Effect of Hybrid Nanofluid}

Figure 7 shows streamlines and isotherms in the cavity for different concentrations of nanoparticles (blue line) compared to pure fluid $(C=0)$ (red line). In Figure $7 \mathrm{a}$, the concentration $(C)$ of nanoparticles is equal to $0.1 \%$. This amount is such that the results for the stream lines and isotherms are very close to each other in the nanofluid and pure fluid. This shows the similarity of the nanofluid and pure fluid properties at this concentration. The values presented for the lowest and highest streamline in the cavity indicate the closeness of the values as well as the line profiles at this concentration. However, the isotherms show similar results. It is expected that the heat transfer at this concentration is close to the results for the pure fluid because the addition of nanoparticles has not significantly affected the fluid properties. As the concentration of the nanoparticle increases, the fluid properties also change, and the results indicate an increase in the difference between the streamline and the isotherms. By reaching a concentration $(C)$ of $0.33 \%$, the flow is enhanced in the center of the cavity but its width decreases and the flow in the porous medium is weakened. Further, by increasing the concentration $(C)$ to 0.75 , the flow in the center continues to increase and the flow is weakened in the porous medium. However, the values inserted on the lines also show a decrease in the flow rate. The decreased flow can be caused by the change in viscosity of the fluid due to the addition of nanoparticles. As the viscosity increases with the increased volume fraction of nanoparticles, the decreased flow velocity in the cavity can be expected by the increased viscosity considering its contrary relationship with the Rayleigh number. This certainly affects heat transfer, as discussed below. By increasing the concentration $(C)$ to $1 \%$ and then $2 \%$, the streamlines are merged at the center of the cavity. On the other hand, the change in the flow regime also changes the profile of the isotherms. 

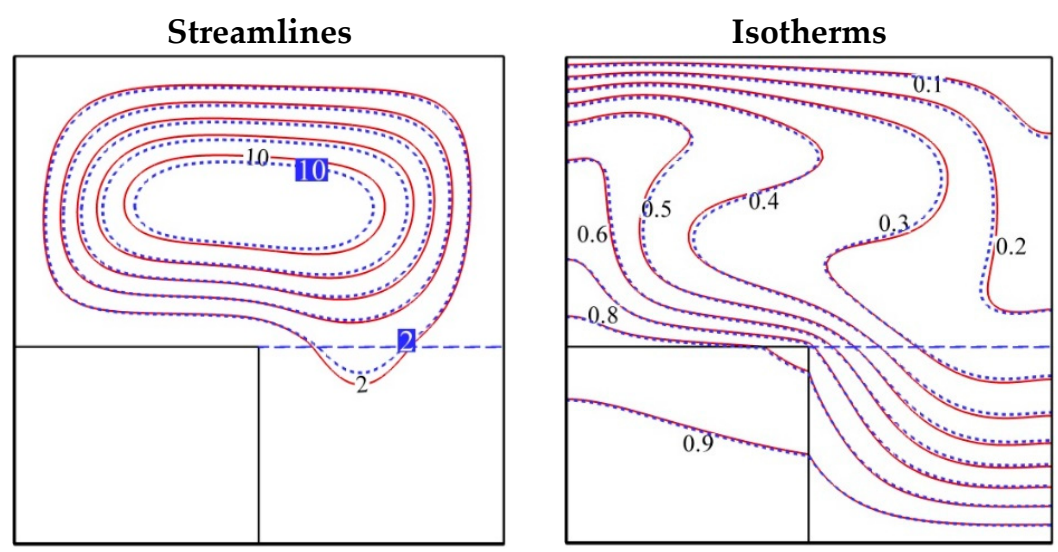

(a) $C=0.1$
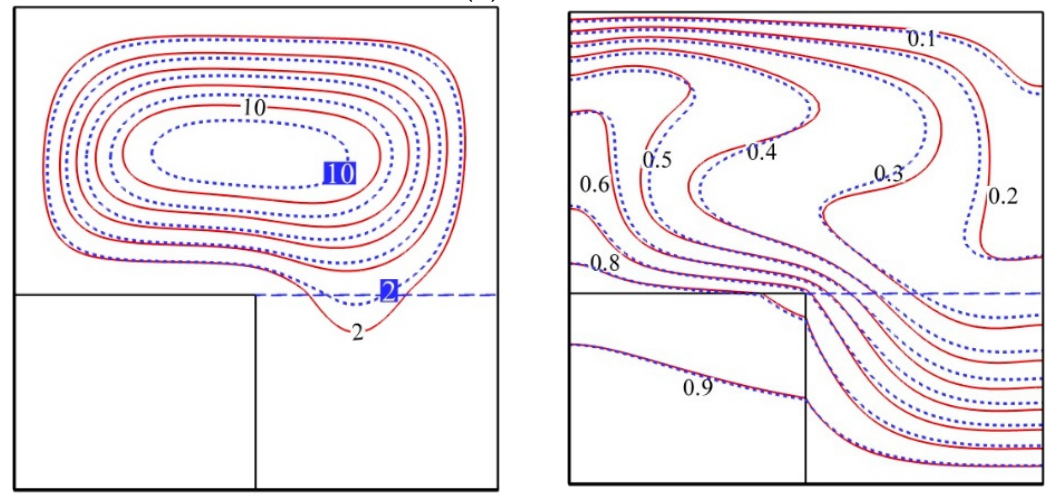

(b) $C=0.33$
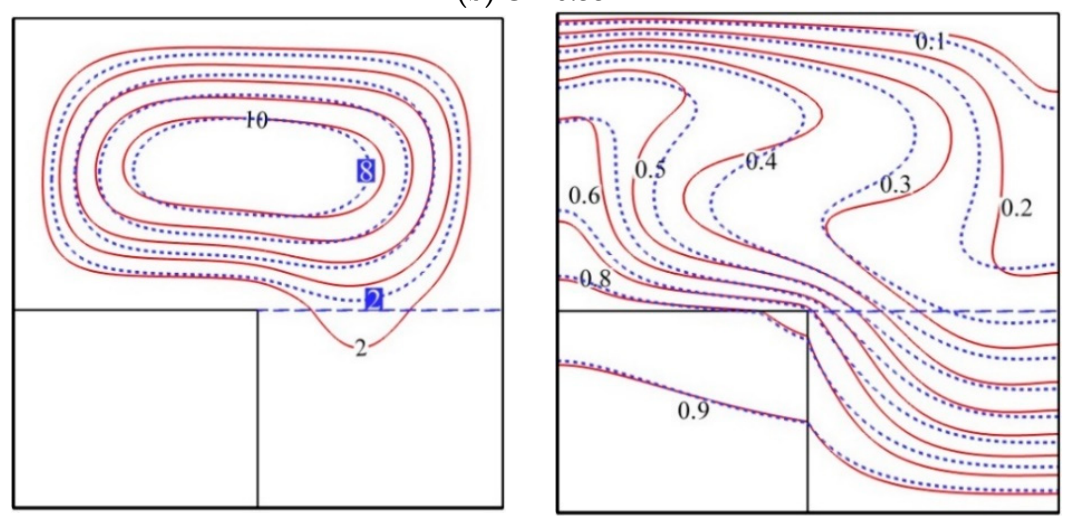

(c) $C=0.75$
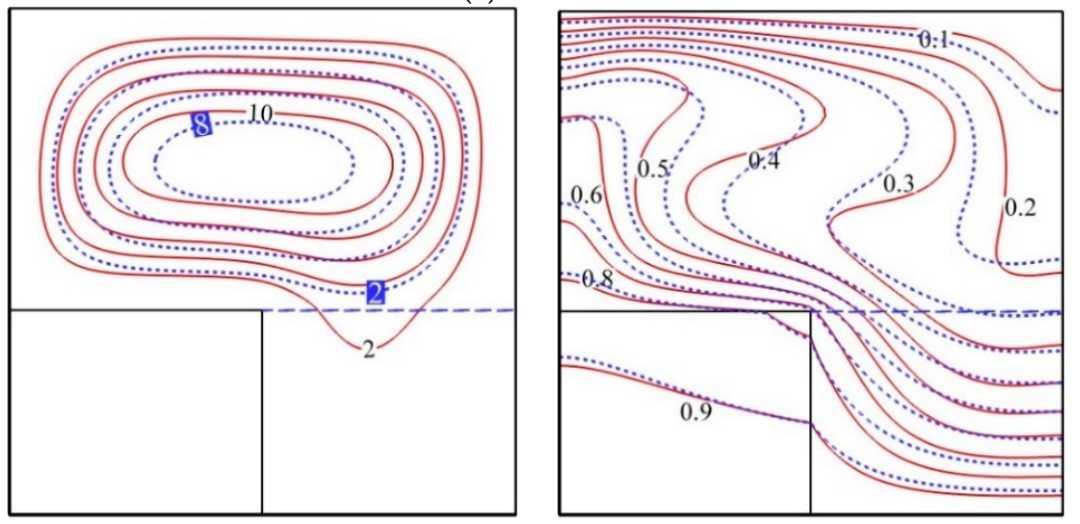

(d) $C=0.75$

Figure 7. Cont. 


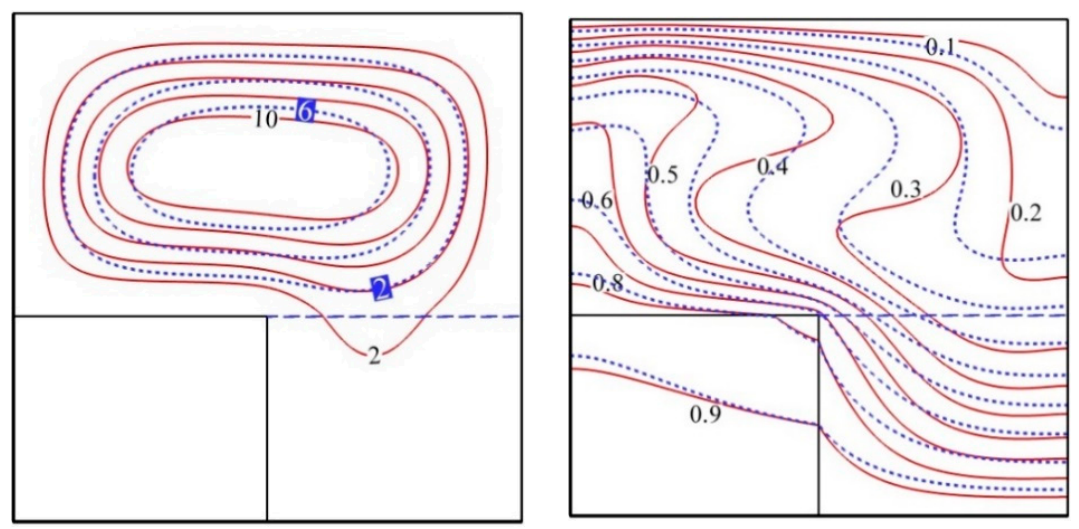

(e) $C=2$

Figure 7. Streamlines and isotherms for different concentrations of nanoparticles (blue line) compared to pure fluid $(\mathrm{C}=0)$ (red line).

Figure 8 shows the Nusselt number as a function of different concentrations of nanoparticles for different Rayleigh numbers. Figure 8 shows that the addition of nanoparticles reduces heat transfer in all Rayleigh numbers, except the Rayleigh numbers $(R a)$ lower than $10^{4}$. It should be noted that the addition of nanoparticles changes the two effective parameters; first, thermal conductivity and second, dynamic viscosity. Both parameters increase with increased concentration. Now, it should be considered that the effect of the increase in which one takes over that of the other, while the increased thermal conductivity increases the heat transfer capacity and the increased dynamic viscosity decreases the heat transfer capacity. The results from Figure 8 indicate that the effect of increased dynamic viscosity takes over the effect of increased thermal conductivity in all Rayleigh numbers, except lower ones, resulting in decreased heat transfer. However, in lower Rayleigh numbers, the effect of increased thermal conductivity takes over the effect of increased dynamic viscosity resulting in enhanced heat transfer.

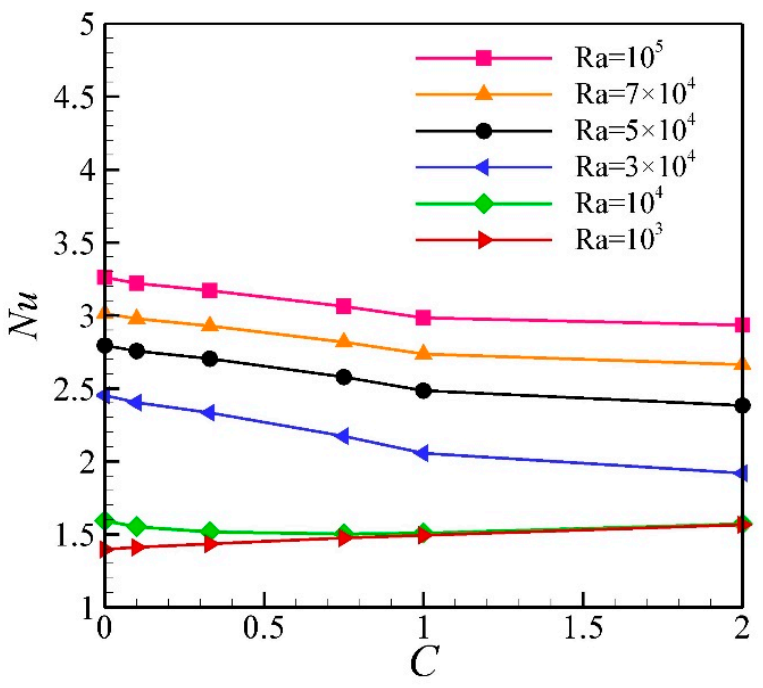

Figure 8. Nusselt of the liquid phase number as a function of the volume concentration of nanoparticles in different Rayleigh numbers.

\subsection{The Effect of Darcy Number (Da)}

Figure 9 shows the effect of the Darcy number on the streamline and isotherms. In Figure 9a, the Darcy number $(D a)$ is equal to $10^{-6}$, indicating a low permeability coefficient for the porous medium. Therefore, the penetration and movement of the nanofluid in the porous matrix is limited and no constant streamline can be seen in the figure related to the streamline lines in the porous medium. 
However, this does not mean the absence of the nanofluid. Rather, it means a slow flow. On the other hand, the isotherms in Figure 9a are almost horizontal due to the negligible fluid motion, indicating the negligible amount of the nanofluid flow in the porous medium and the lack of strength of the nanofluid circulation in this region. In Figure $9 \mathrm{~b}$, by increasing the Darcy number $(D a)$ to $10^{-4}$ and increasing the permeability, the flow is enhanced in the porous region and the streamlines are also inclined partially to this region, indicating increased flow circulation in this porous region. The isotherms for the aforementioned Darcy number have also confirmed this conclusion as the isotherms have changed under the influence of the nanofluid flow. In Figure 9c, by increasing the Darcy number $(D a)$ to $10^{-3}$, the flow in the porous region is dramatically enhanced and streamlines are distributed in this region. Due to the enhancement of the nanofluid flow circulation, the isotherms have also changed and become almost vertical in the vicinity of the solid medium, indicating the enhancement of the flow and the convection mechanism in the vicinity of the solid medium.

(a) $D a=10^{-6}$

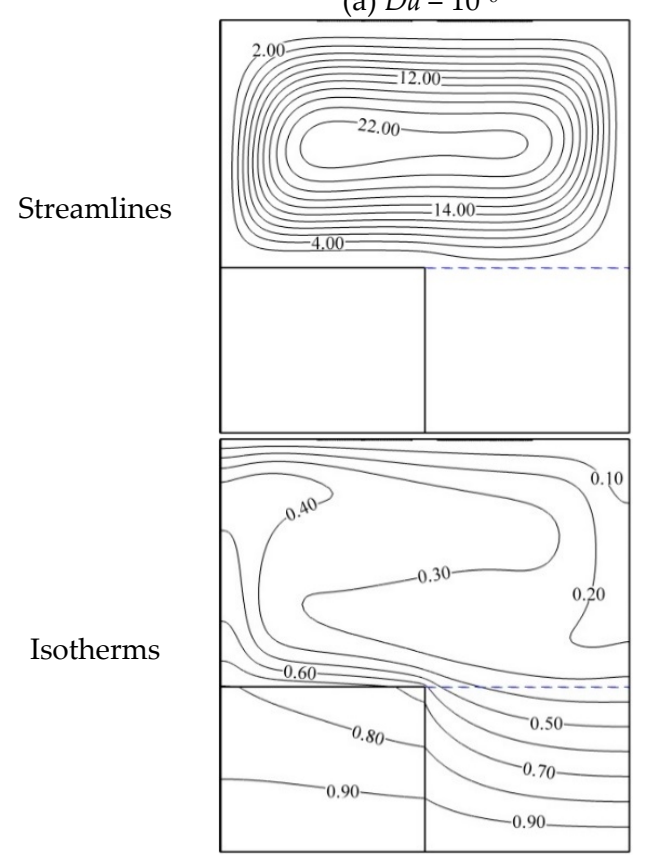

(b) $D a=10^{-4}$

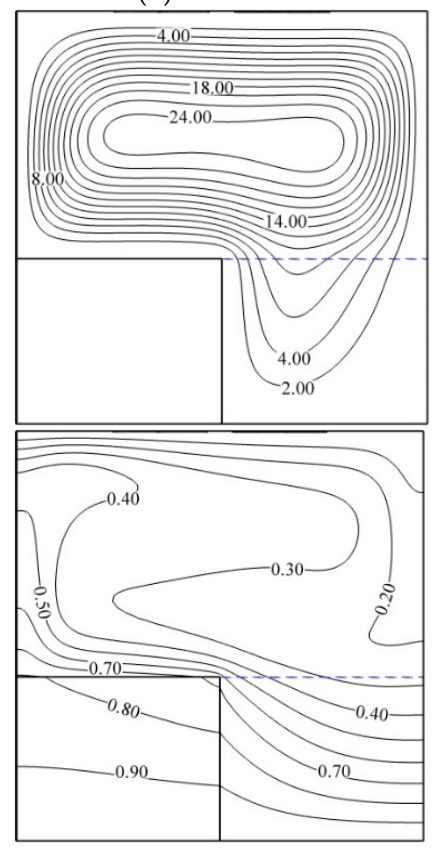

(c) $D a=10^{-3}$

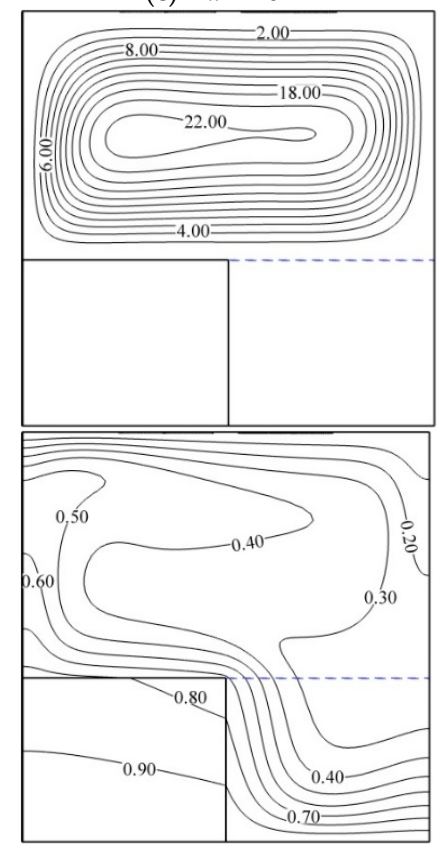

Figure 9. Streamline and isotherms for different values of Darcy number. (a) $D a=10^{-6}$ (b) $D a=10^{-4}$ (c) $D a=10^{-3}$.

Figure 10 shows the Nusselt number for the different values of the Darcy number. According to Figure 9, the increase in the Darcy number means increased permeability and, consequently, an increased flow in the cavity. Now, it can be seen in Figure 10 that the hybrid nanofluid Nusselt number increases with the increase in the Darcy number, indicating increased heat transfer.

Figure 11 shows the hybrid nanofluid local Nusselt number on the cold wall for different values of the Darcy number. As explained in the previous figure (Figure 10), an increase in the Darcy number leads to increased heat transfer. This also applies to local Nusselt and follows the same pattern. On the other hand, the profiles of the local Nusselt number are similar in different Darcy numbers; they only differ in values. In addition, the maximum local Nusselt occurs on the left side of the cold wall in about $X=0.2$, which can be seen in Figure 11 by the high accumulation of the isotherms in this region. 


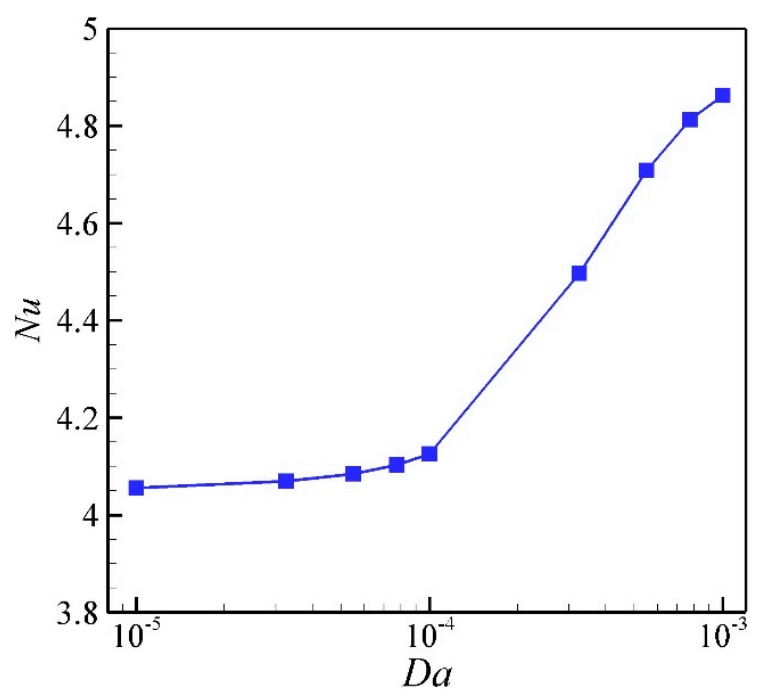

Figure 10. Hybrid nanofluid Nusselt number for different values of the Darcy number.

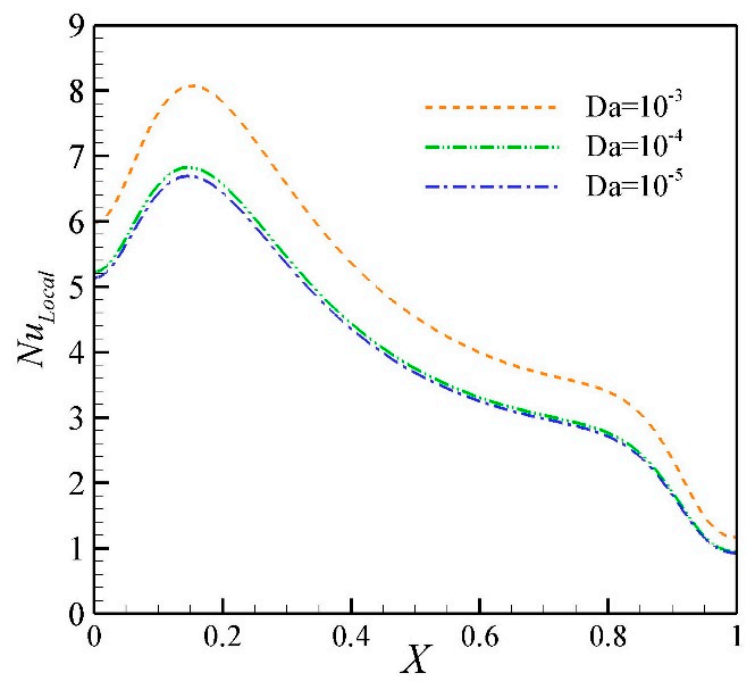

Figure 11. Local Nusselt number of hybrid nanofluid for different values of Darcy number.

\subsection{The Effect of Porosity Coefficient ( $\varepsilon$ )}

Figure 12 shows the effect of the porosity coefficient on the streamline and isotherms. In Figure 12a, the porosity coefficient $(\varepsilon)$ is equal to 0.1 . Due to the low amount of porosity coefficient, there is a small portion of void space to be filled with the fluid and streamline lines in the figure have a low accumulation in the porous medium. This reduces the flow circulation in the entire cavity and the isotherms in the porous medium have a low accumulation in the vicinity of the walls. By increasing the porosity, the circulation of the nanofluid flow improves gradually in the porous medium, and when the porosity $(\varepsilon)$ is equal to 0.4 , nanofluid circulates well in the porous medium. This has led to the high accumulation of the isotherms in the vicinity of the walls. On the other hand, considering the values inserted on the streamline lines, the increased porosity has led to an increased flow. 

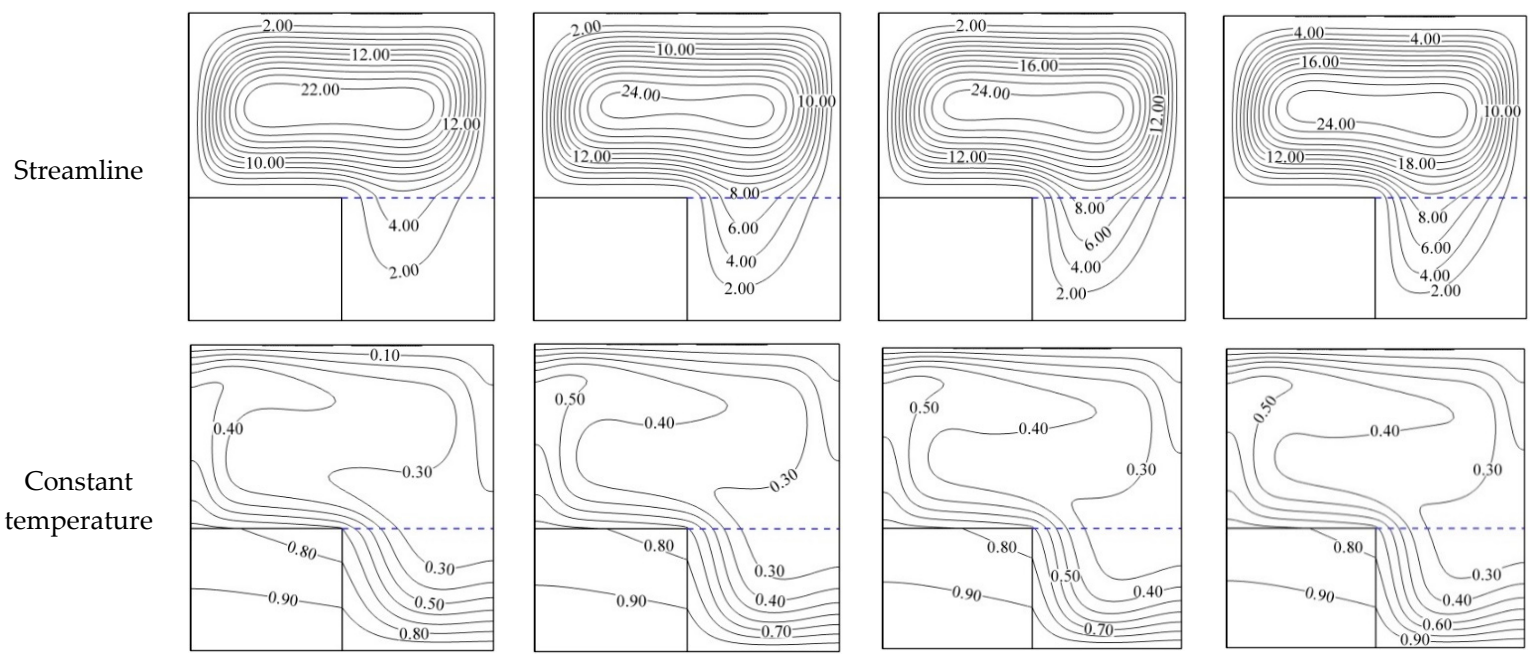

(a) $\varepsilon=0.1$

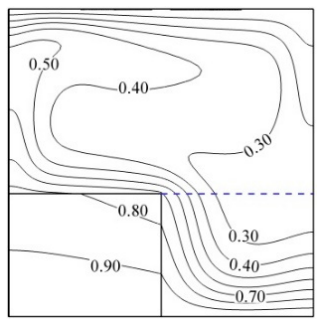

(b) $\varepsilon=0.2$

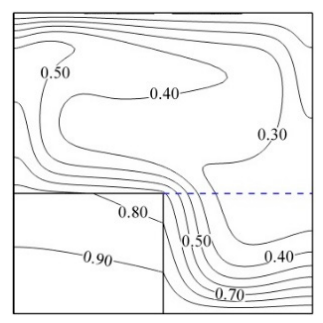

(c) $\varepsilon=0.3$

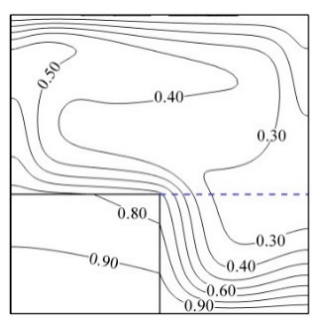

(d) $\varepsilon=0.4$

Figure 12. The effect of porosity coefficient on the streamline and isotherms. (a) $\varepsilon=0.1$, (b) $\varepsilon=0.2$, (c) $\varepsilon=0.3$, (d) $\varepsilon=0.4$.

Figure 13 shows the Nusselt number for different values of porosity coefficient. Increasing the porosity coefficient means the enhancement of the flow in the porous medium. This has been shown in Figure 12 in the form of streamline lines. Therefore, the enhancement of flow in the cavity causes the enhanced convective mechanism and increase heat transfer. Figure 13 demonstrates that the Nusselt number increases with increased porosity, indicating increased heat transfer in the cavity.

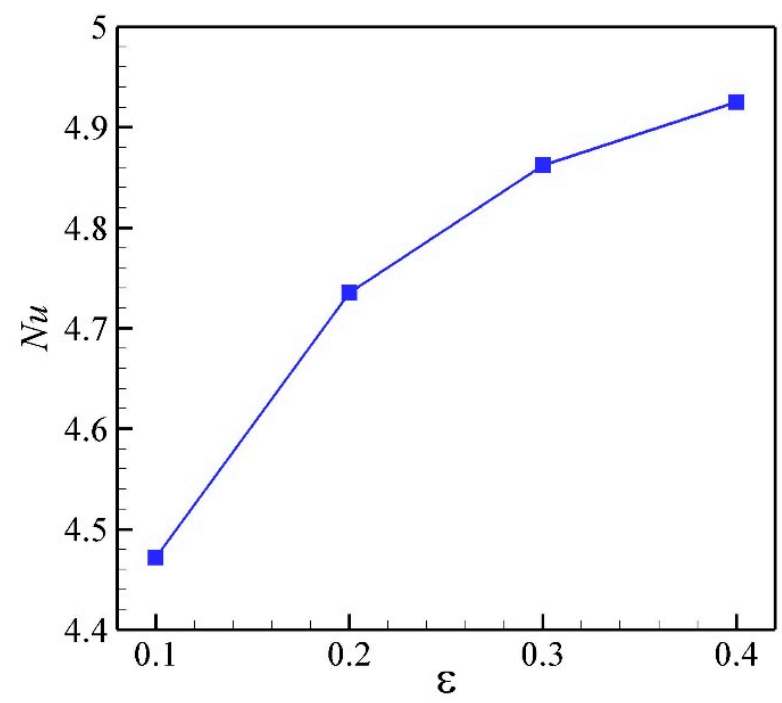

Figure 13. Nusselt number of the hybrid nanofluid for different values of porosity coefficient.

Figure 14 shows the local Nusselt number of the hybrid nanofluid on the cold wall for different values of porosity coefficient. As shown in the previous figure (Figure 12), increasing the porosity coefficient leads to the increased heat transfer. This is also evident in the present figure and the local Nusselt number has also increased with the increase in the porosity coefficient. The profile of the local Nusselt number is also such that its maximum has occurred at about $X=0.2$, caused by the flow regime in the cavity. This, of course, has already been shown in Figure 14 in the isotherms, where the isotherms have the highest accumulation on the left side of the wall. 


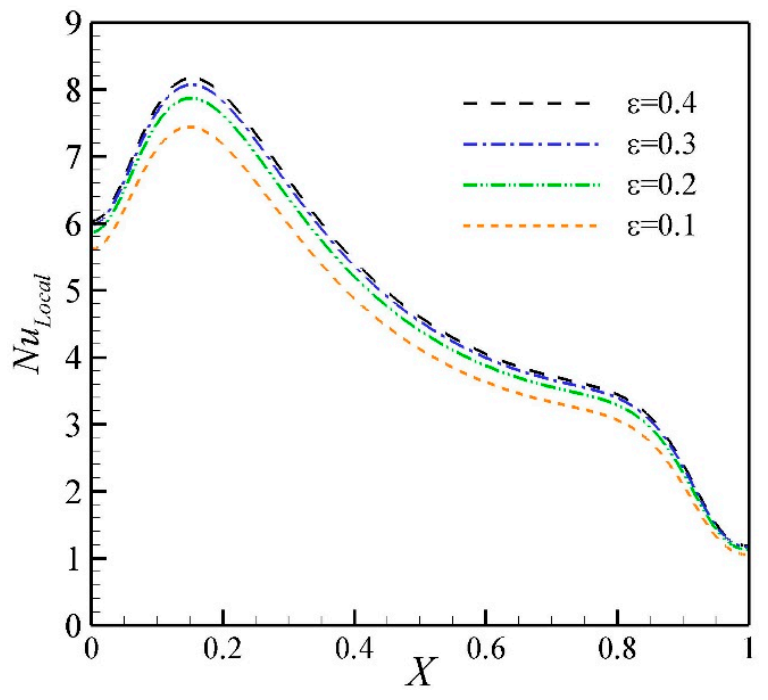

Figure 14. Local Nusselt number of the hybrid nanofluid for different values of porosity coefficient.

\subsection{The Effect of the width (D) of Solid and Porous Media}

Figures 15 and 16 show the effect of changing the width of the solid and porous medium $(D)$ on the streamline and isotherms. The height of the solid and porous media is constant and only the location of the interface between the two media, which is indicated by the parameter $D$, is changed. Figure 15a shows the isotherms for $D=0.9$. Due to the decrease in the width of the porous medium, the heat transfer occurs mainly from the solid medium to the cavity.

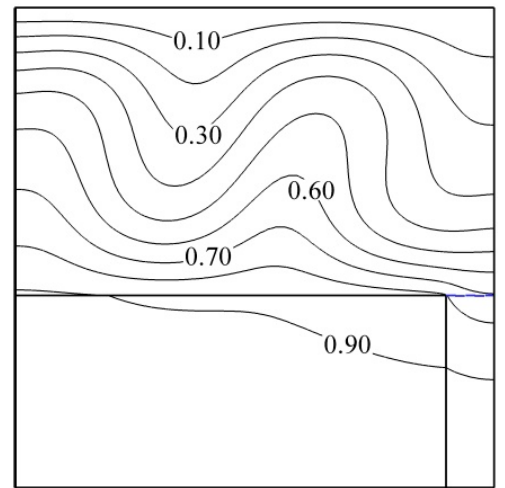

(a) $D=0.9$

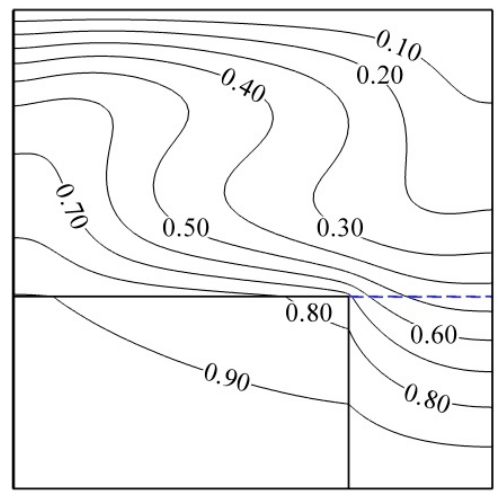

(d) $D=0.6$

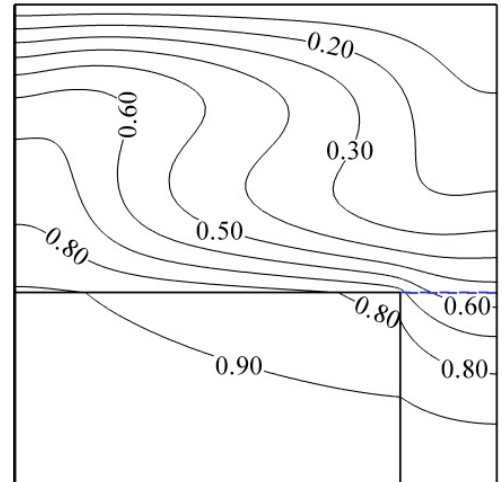

(b) $D=0.8$

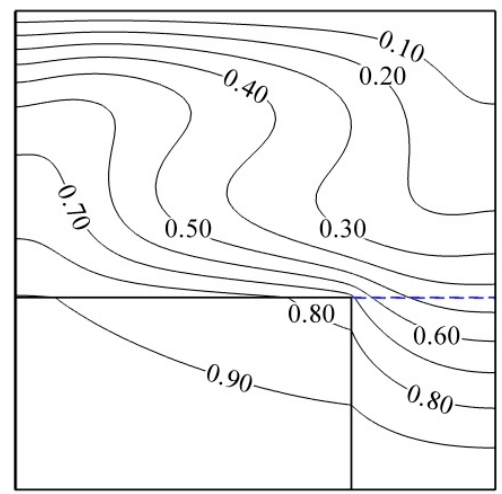

(e) $D=0.5$

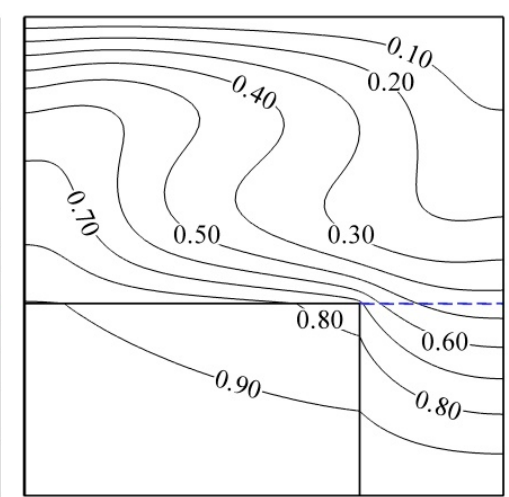

(c) $D=0.7$

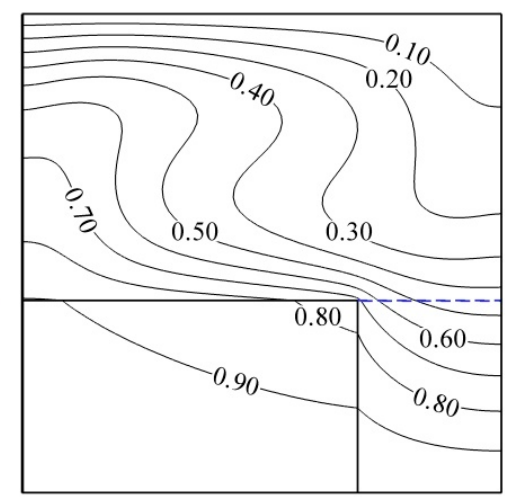

(f) $D=0.4$

Figure 15. Cont. 


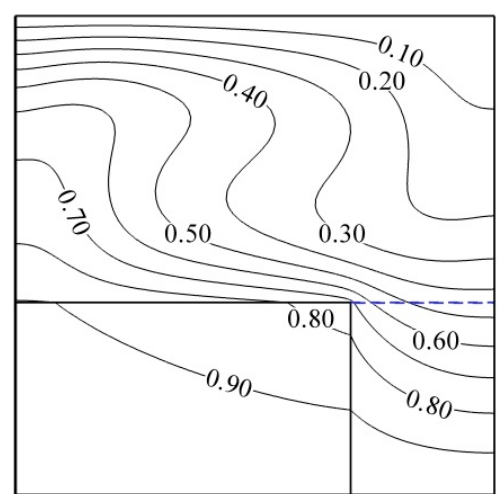

(g) $D=0.3$

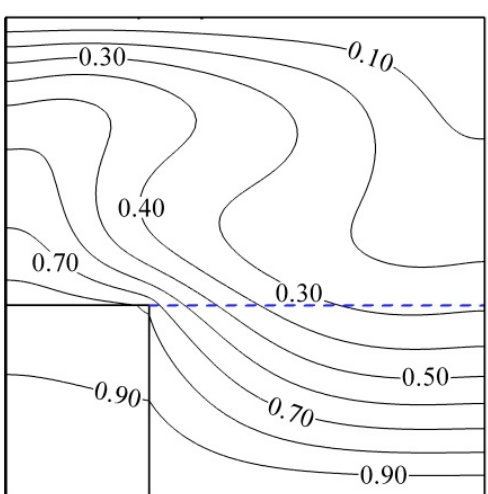

(h) $D=0.2$

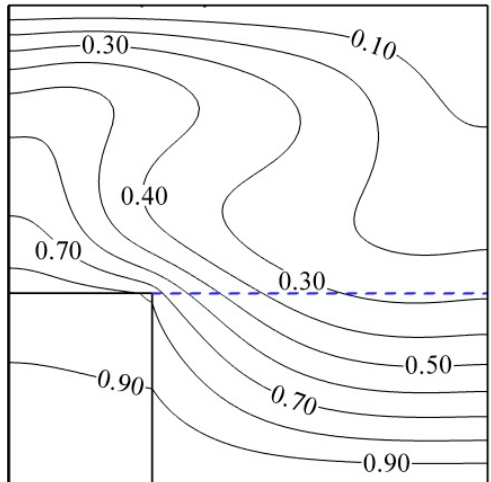

(i) $D=0.1$

Figure 15. Isotherms for different values of the width of solid and porous medium.

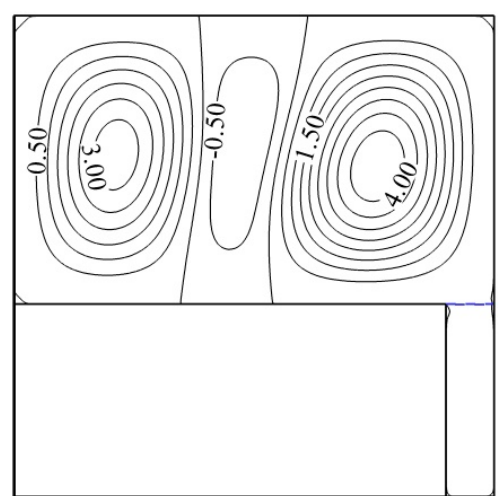

(a) $D=0.9$

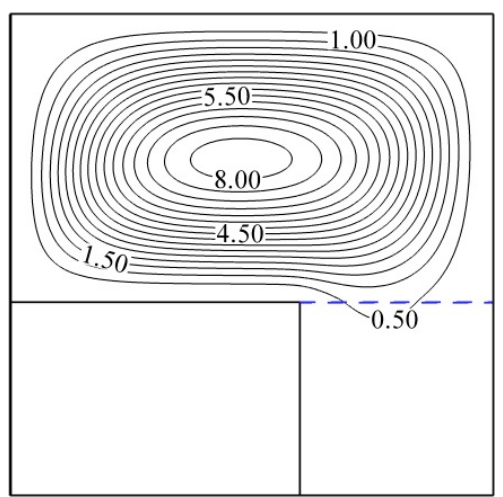

(d) $D=0.6$

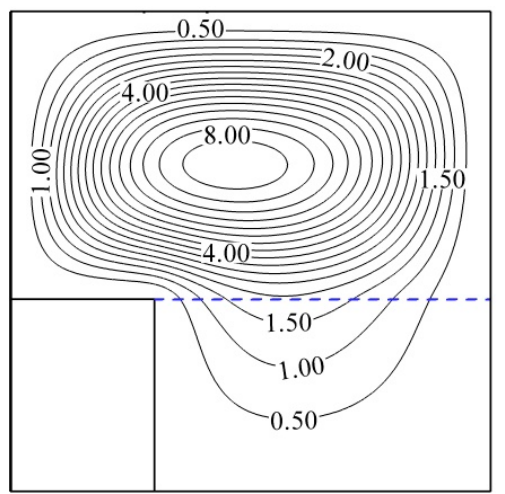

(g) $D=0.3$

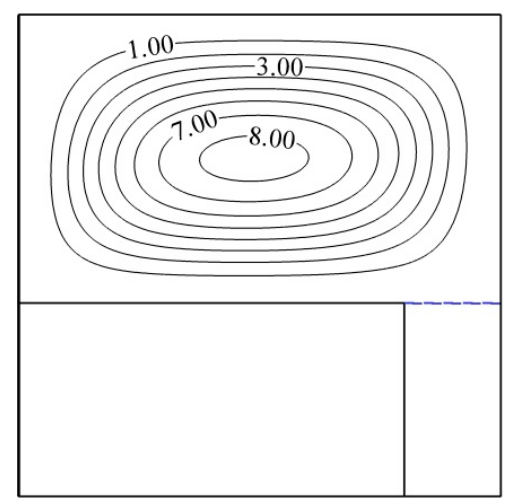

(b) $D=0.8$

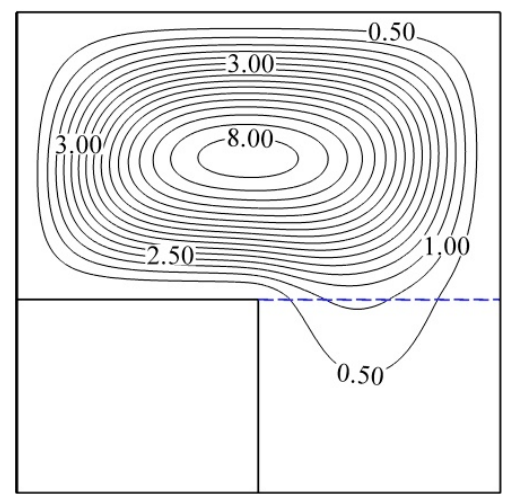

(e) $D=0.5$

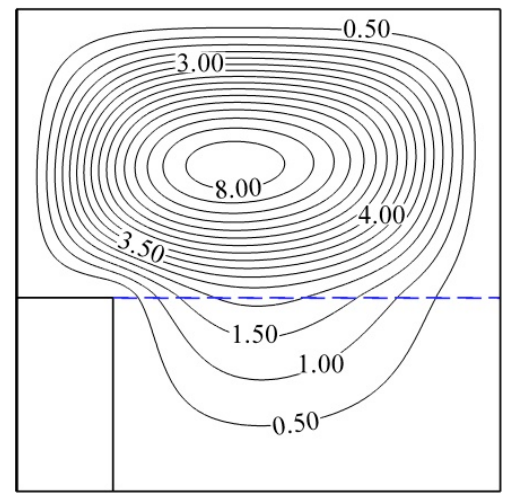

(h) $D=0.2$

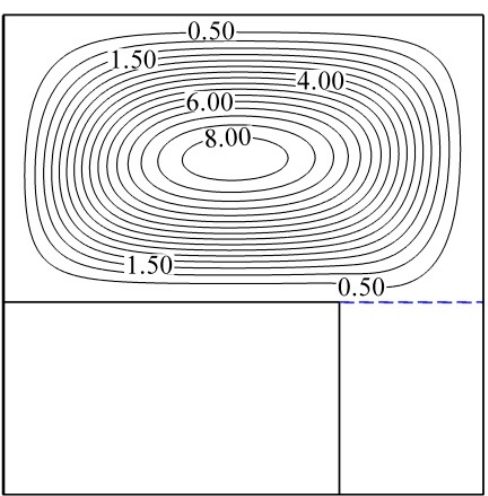

(c) $D=0.7$

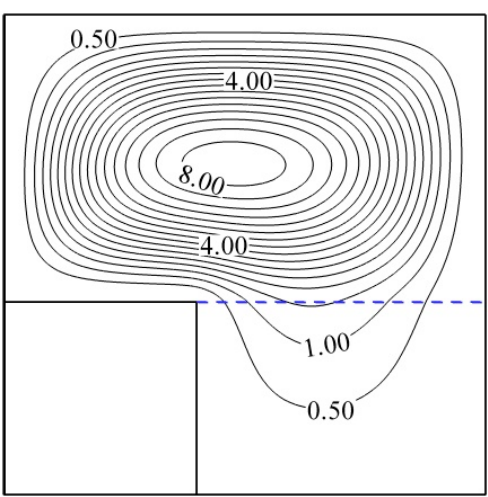

(f) $D=0.4$

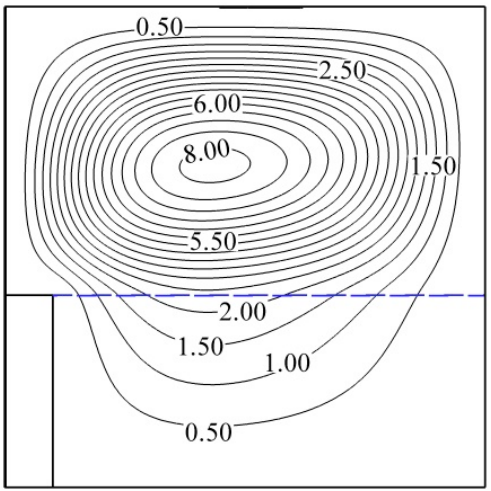

(i) $D=0.1$

Figure 16. The streamlines for different values of the width of solid and porous medium. 
In the nanofluid- filled portion, the isotherms are as such that they indicate the lack of strong circulation of nanofluid. By decreasing the width to $D=0.8$, nanofluid obtains more freedom such that the isotherms indicate it. Further, by decreasing the width of the solid medium and the porous medium to $D=0.1$, the line $\theta=0.9$ continues to cut the solid medium. This is due to the high conductivity of the solid medium which is almost at a hot temperature.

Figure 16 shows the effect of changing the width of the solid and the porous media $(D)$ on the streamline lines. As shown in Figure 15, when the width of the solid medium is considered as $D=0.9$, the heat transfer occurs mainly from the solid media, while the mechanism only causes the bottom heating in the nanofluid- filled portion. Although it was already said that a part of the heat transfer occurs from the vicinity of the solid medium due to its presence, it can be seen in Figure 16a that the heat transfer from the vicinity of the solid medium is practically negligible due to the significant decrease in the width of the porous medium and the occurrence of the bottom heating and the formation of Rayleigh-Benard vortices are evident. By increasing the width of the porous medium, the nanofluid enclosed in the porous matrix obtains more freedom and the fluid circulates freely in the entire cavity by exchanging heat with the solid medium. Thus, in Figure 16b, we can see the elimination of Rayleigh-Benard vortices and the formation of a general vortex in the cavity. However, in Figure 16d, the flow in the porous medium is negligible up to $D=0.6$. By increasing the width of the porous medium, the freedom of the fluid and the enhancement of the flow occur in the porous medium so that the enhancement reaches its maximum in $D=0.1$, and the flow lines are significantly enhanced in the porous medium.

\subsection{The Effect of the Height (W) of Solid and Porous Media}

Figures 17 and 18 show the streamline and isotherms for different values of the height $(W)$ of the porous and solid media. It is clear that the given parameter ranges from 0 to 1 , and as the number goes up, the height of the solid and porous media increase simultaneously and the nanofluid-filled medium is narrowed. Additionally, by decreasing it, the height of the solid and porous medium decreases simultaneously, leading to an increase in the nanofluid-filled medium. The results from Figure 17 for the streamline lines indicate that increasing the parameter $W$ actually leads to splitting the cavity in two. Figure 17a shows the streamline lines only in the right half of the cavity, which is filled with porous medium, and the space between the solid medium and the cold wall is actually without flow. This definitely affects the heat transfer in the cavity. By reducing the amount of $W$ and increasing the volume between the solid medium and the cold wall, the path for the nanofluid circulation is opened, and as the parameter $W$ decreases, the flow lines move toward this region. However, in Figure $17 \mathrm{~d}$ where $W=0 / 6$, we see the formation of Riley-Benard vortices in the distance between the solid medium and the cold wall, because the solid medium is approximately at a hot temperature. In addition, a larger vortex contains the porous medium and a half of the nanofluid medium. On the other hand, the larger vortex circulates in a clockwise direction and the Rayleigh-Benard vortex circulates in a counterclockwise direction according to the sign of the values inserted. The effect of this for the heat transfer in the cavity should be considered. Further, with a greater decrease in the height of two solid and porous media, we continue to see the formation of the central and single vortices. By reaching $W=0.1$, due to the significant decrease in the height of the solid medium, the flow regime acts in such a way that a small counterclockwise vortex is created in the upper corner of the cavity. This vortex is not a Rayleigh-Benard vortex, and only the flow regime created causes its formation.

Figure 18 shows the isotherms for different values of the height $(W)$ of the porous and solid media. The above figures are equivalent to Figure 17 and will be compared to them. In Figure 18a, due to the great height of the solid medium, the heat has not been able to penetrate completely into the solid medium and the temperature lines cut it many times. The above figure shows that the upper boundary of the solid medium is at an average temperature $(\theta)$ of 0.5 . This causes the upper boundary to have a low temperature, and due to its low difference with the cold wall temperature $(\theta=0)$ and the spatial constraints of this region, the lack of fluid circulation in the interface between the solid medium and 
the cold wall in accordance with Figure 18a is justifiable. However, the point that is important in Figure 18a is the great height of the solid medium and its relatively high temperature compared to the circulating nanofluid, causing the formation of the heat transfer from the adjacent side in the half of the cavity. It is important to consider how the heat transfer occurs in the cavity in these conditions. By continuing the decrease in the parameter $W$, the solid and porous media becomes smaller, causing an increase in the space for the nanofluid to circulate at the top of the cavity. This has led to a change in the isotherms considering the flow regime in the cavity. Finally, in the case of $W=0.1$, the solid medium is at a completely hot temperature, justifying the failure of the temperature lines to cut the solid medium.

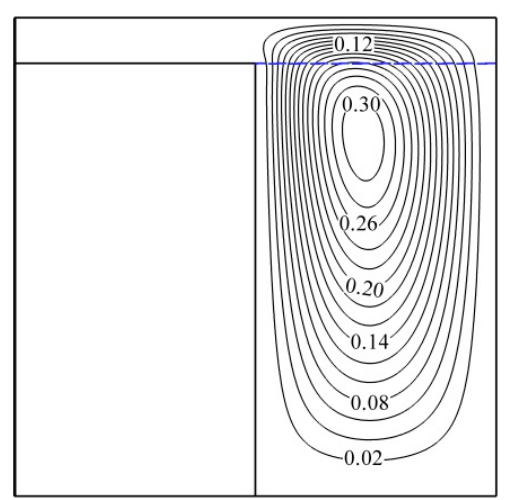

(a) $W=0.9$

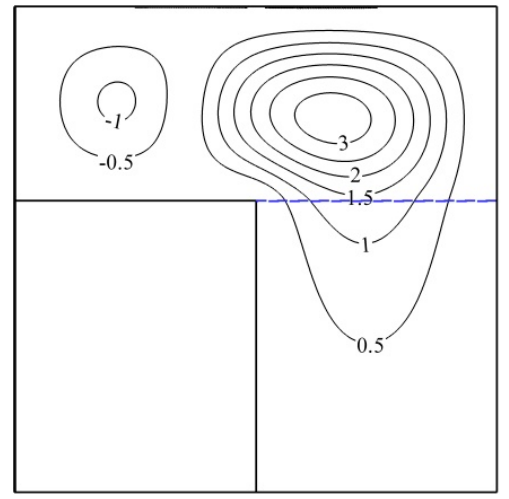

(d) $W=0.6$

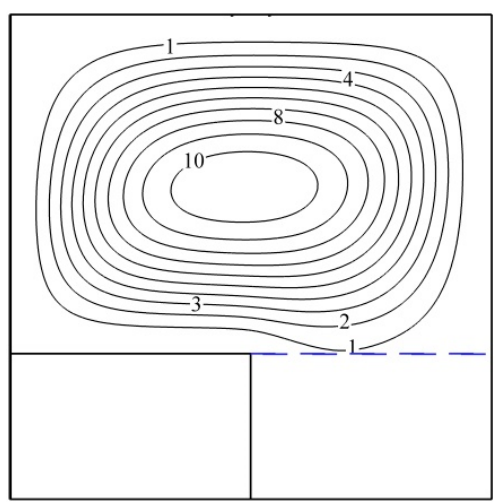

(g) $W=0.3$

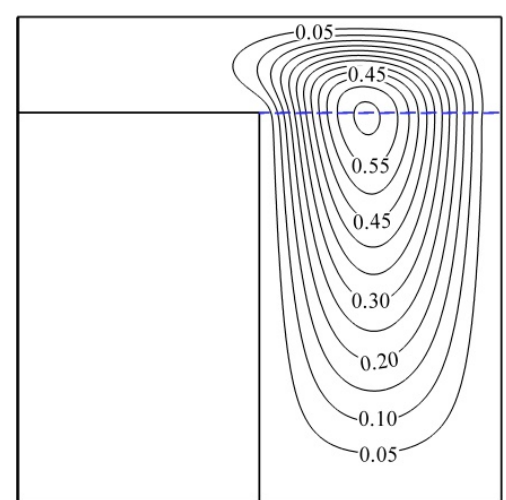

(b) $W=0.8$

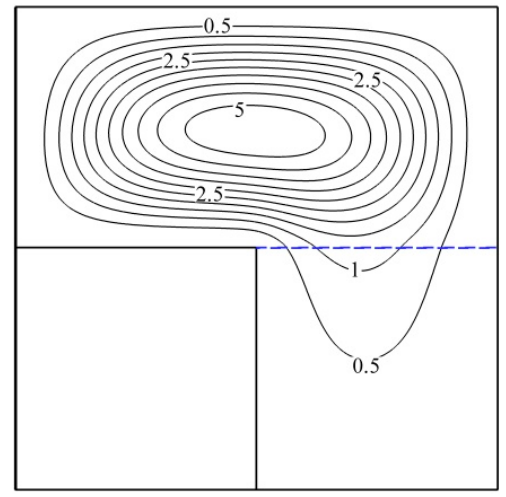

(e) $W=0.5$

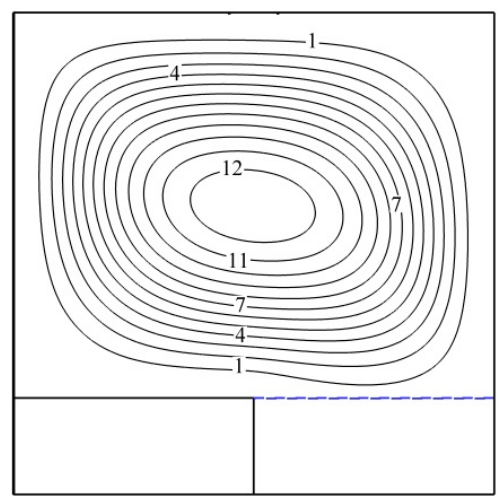

(h) $W=0.2$

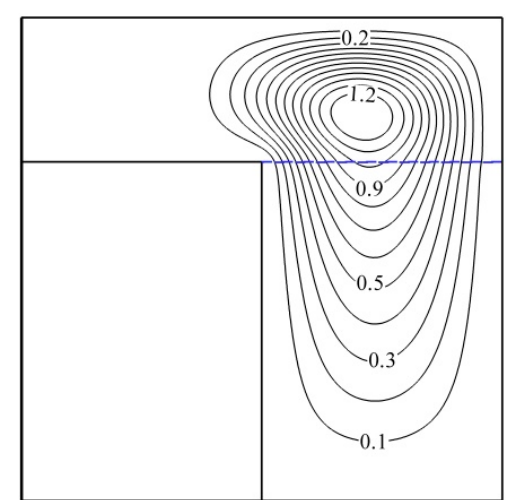

(c) $W=0.7$

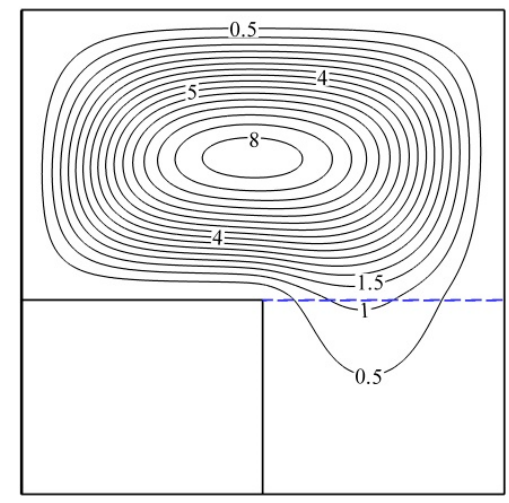

(f) $W=0.4$

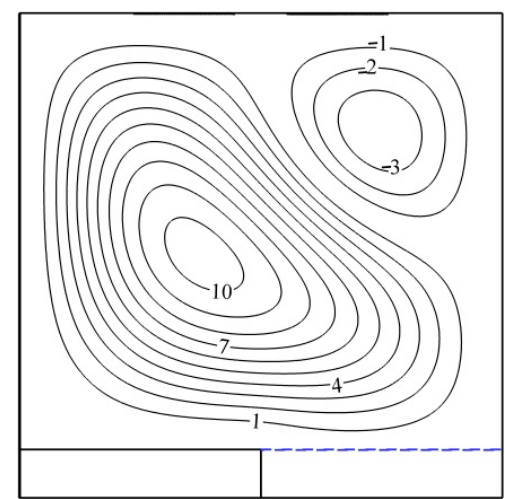

(i) $W=0.1$

Figure 17. Streamline lines for different values of the height of the solid and porous media. 


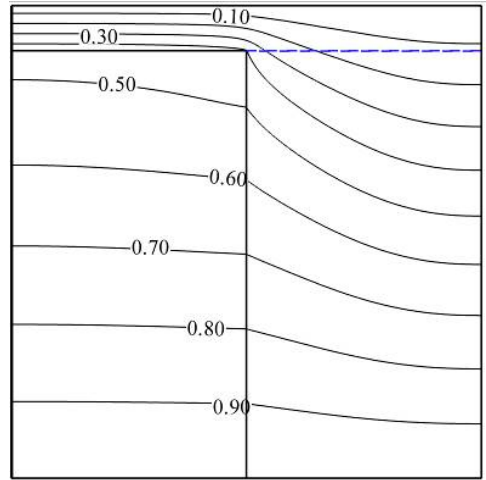

(a) $W=0.9$

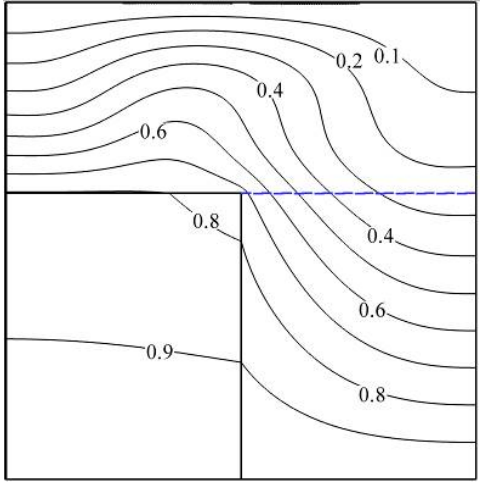

(d) $W=0.6$

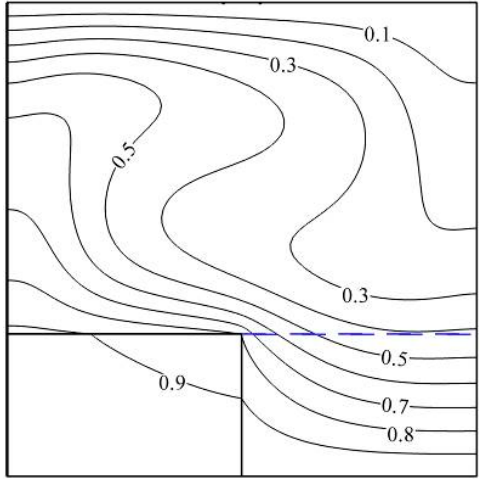

(g) $W=0.3$

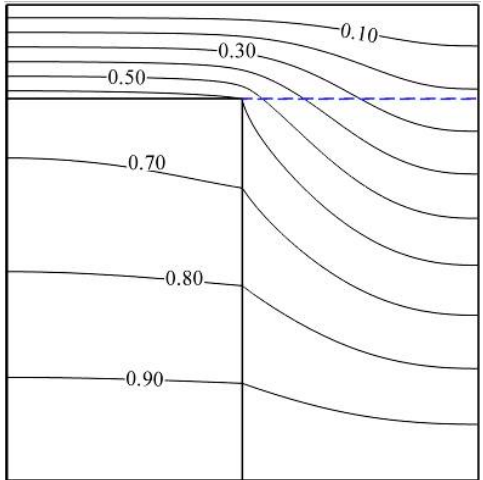

(b) $W=0.8$

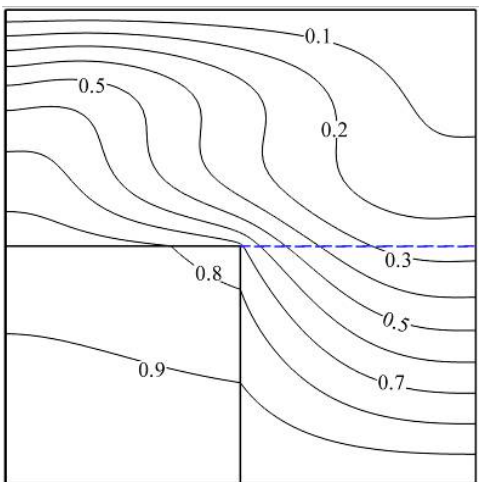

(e) $W=0.5$

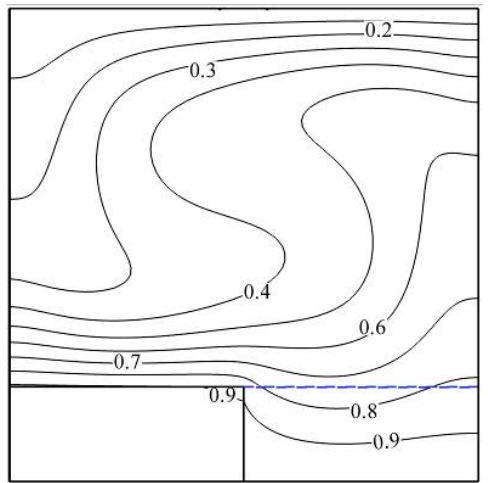

(h) $W=0.2$

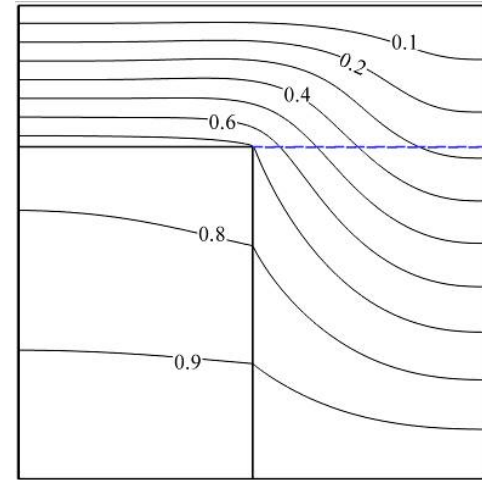

(c) $W=0.7$

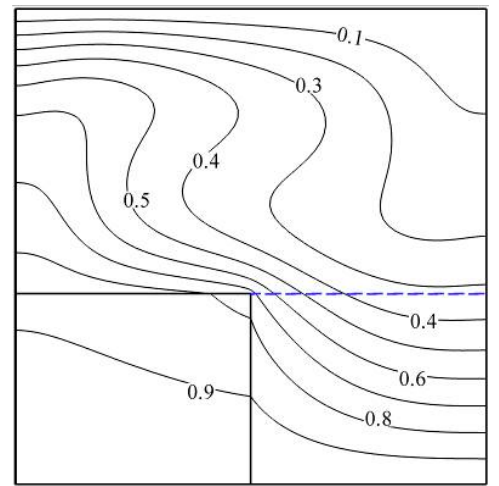

(f) $W=0.4$

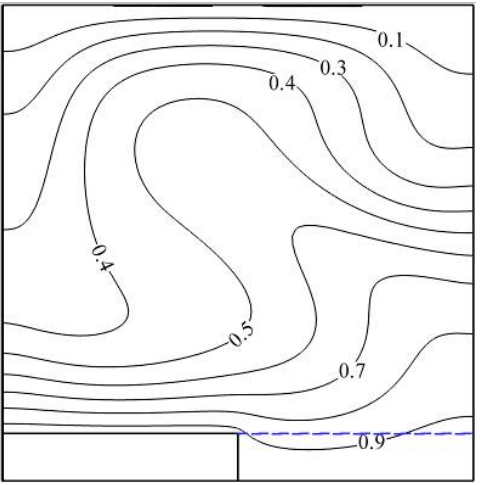

(i) $W=0.1$

Figure 18. The isotherms for different values of the height of the solid and porous media.

Figure 19 shows the Nusselt number for the different values of the height $(W)$ of the solid and porous media. As shown in Figures 17 and 18 for the streamline and isotherms, changes in this parameter result in major changes in the flow regime in the cavity, where only one vortex is formed in the cavity, or two vortices are formed in the cavity at some values of $W$. However, the Rayleigh-Benard vortex is formed on top of the solid medium at $W=0.6$. Now, we examine the effect of each of the above values on the heat transfer. Figure 19 shows that the maximum Nusselt number occurs in $W=0.9$, where the height of the solid and porous media is such that the nanofluid circulates in half of the cavity. In this amount of $W$, heat is transferred mainly to the nanofluid not from the bottom of the cavity, but from the solid wall in the vicinity of the nanofluid. However, the minimum Nusselt number occurs in $W=0.7$. On the other hand, an acceptable Nusselt number is obtained where $W=0.1$. At this amount of $W$, the height of the solid and porous media is minimized and the nanofluid-filled medium has a large volume. The reason for this is the increased volume of the nanofluid portion which has greater space in the cavity for the fluid circulation with the decreased height of the solid and 
porous media (especially the solid medium), making it easy to circulate fluid, increase fluid velocity and consequently increase heat transfer.

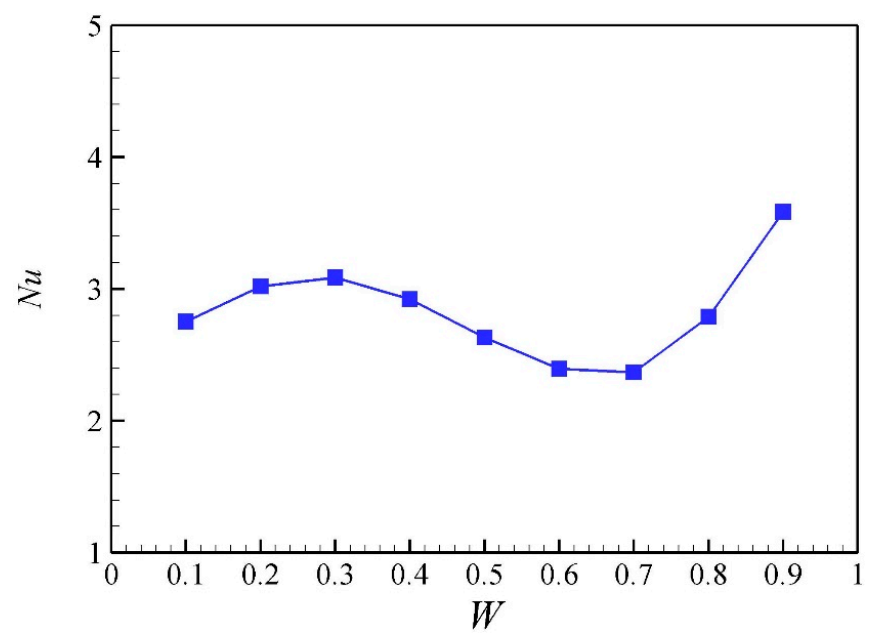

Figure 19. Nusselt number for different values of the height of the solid and porous media.

\section{Conclusions}

In the present study, the free convection heat transfer of hybrid nanofluids in a closed cavity was investigated considering the porous and solid media. The cavity was in a square form such that its bottom and top walls were assumed to be insulated in hot and cold temperatures, respectively. The cavity was divided into three portions, including a portion filled with hybrid nanofluids, a porous medium, and a solid medium. In this way, the cavity was analyzed considering the bottom wall heating. The portion filled with hybrid nanofluids contained copper and aluminum oxide hybrid nanoparticles of 20 to $40 \mathrm{~nm}$ in size. The governing equations for the nanofluid portion with a homogeneous form were extracted assuming thermal non-equilibrium between the porous and solid media and have been converted to their non-dimensional form. The problem was solved numerically using the finite element method. Subsequently, the important parameters affecting the heat transfer from the cavity were discussed and the effect of each on the heat transfer was measured. The results were presented in figures, tables, curves, and contours, and were discussed in detail. The results indicate that in the hybrid nanofluid portion, the heat transfer can be enhanced by adding nanoparticles to the base fluid, while the viscosity overcomes the thermal conductivity and impairs the heat transfer with an increase in nanoparticles volume concentration. In the porous medium, increasing the ratio of nanofluid conductivity to the porous matrix, Darcy number, and porosity coefficient causes the decreased heat transfer, the increased heat transfer, and the increased heat transfer, respectively. The solid portion is also directly related to the ratio of the solid conductivity to the nanofluid, and its increase leads to enhanced heat transfer. In addition, increasing the Rayleigh number causes increased heat transfer, and the increase in the volume of the nanofluid portion enhances heat transfer due to the enhancement of the nanofluid circulation. Some important conclusions are as follows:

(1) Adding nanoparticles to the pure fluid can decrease or increase heat transfer when considering Rayleigh number. The addition of nanoparticles changes two effective parameters: thermal conductivity and second, dynamic viscosity, while both parameters increase by adding nanoparticles. However, in lower Rayleigh numbers, the effect of increased thermal conductivity overcomes the effect of increased dynamic viscosity and the addition of the nanoparticles and the increased volume fraction results in the increased heat transfer in the cavity. In higher Rayleigh numbers, the effect of increased dynamic viscosity overcomes the effect of increased thermal conductivity and the addition of the nanoparticles and the increased volume fraction results in the decreased heat transfer in the cavity. 
(2) The effect of the Darcy number as a non-dimensional permeability on the heat transfer in the cavity has a direct effect so that with its increase, the heat transfer is increased and with its decrease, the heat transfer is decreased.

(3) The porosity coefficient is directly related to the heat transfer and, as it increases or decreases, heat transfer either increases or decreases.

(4) The change in the width of the solid and porous media causes a change in the flow regime in the cavity and has an increasing or decreasing effect on the heat transfer.

(5) The change in the height of the solid and porous media cause a change in the flow regime in the cavity and has an increasing or decreasing effect on the heat transfer.

(6) The relationship between the Rayleigh number and the heat transfer is direct, and its increase or decrease can increase or decrease heat transfer in the cavity.

Author Contributions: All authors contributed in the paper equally.

Funding: This research received no external funding.

Conflicts of Interest: No conflict of interest.

\section{Nomenclature}

\section{Latin Symbols}

C nanoparticle volume concentration \%

$C_{p} \quad$ Heat capacity

$d \quad$ solid-porous medium length [m]

$D a \quad$ Darcy number

$g$ gravitational acceleration $\left[\mathrm{m} / \mathrm{s}^{2}\right]$

$H$ heat transfer coefficient of porous medium

$k \quad$ thermal connectivity $[\mathrm{W} / \mathrm{m} \cdot \mathrm{K}]$

$L \quad$ cavity Length [m]

$\mathrm{Nu} \quad$ Nusselt number

$P \quad$ Pressure [Pa]

Pr Prandtl number

$\mathrm{Ra} \quad$ Rayleigh number

$T$ temperature [K]

$u \quad$ velocity component along $\mathrm{x}$-direction $[\mathrm{m} / \mathrm{s}]$

$v \quad$ velocity component along $\mathrm{y}$-direction $[\mathrm{m} / \mathrm{s}]$

$w \quad$ solid-porous medium height [m]

$x \quad$ location component along $\mathrm{x}$ direction

$y \quad$ location component along $\mathrm{y}$ direction

Greek symbols

$\alpha \quad$ effective thermal diffusivity $\left[\mathrm{m}^{2} / \mathrm{s}\right]$

$\beta \quad$ thermal expansion coefficient $[1 / \mathrm{K}]$

$\theta \quad$ Non-dimensional temperature

$v \quad$ kinematic viscosity $\left[\mathrm{m}^{2} / \mathrm{s}\right]$

$\rho$ density $\left[\mathrm{kg} / \mathrm{m}^{3}\right]$

$\Psi$ flow function

Subscripts

c Cold

h Hot

s Solid

f pure fluid

hnf hybrid nanofluid

hnp Nanoparticle 


\section{References}

1. Bejan, A. Convection Heat Transfer; John Wiley \& Sons: New York, NY, USA, 2013.

2. De Vahl Davis, G. Natural convection of air in a square cavity: A bench mark numerical solution. Int. J. Numer. Methods Fluids 1983, 3, 249-264. [CrossRef]

3. Turan, O.; Poole, R.J.; Chakraborty, N. Influences of boundary conditions on laminar natural convection of Bingham fluids in rectangular enclosures with differentially heated side walls. Heat Transf. Eng. 2014, 35, 822-849. [CrossRef]

4. Deng, Q.H.; Tang, G.F. Numerical visualization of mass and heat transport for mixed convective heat transfer by streamline and heatline. Int. J. Heat Mass Transf. 2002, 45, 2387-2396. [CrossRef]

5. Sathiyamoorthy, M.J.; Chamkha, A. Analysis of natural convection in a square cavity with a thin partition for linearly heated side walls. Int. J. Numer. Methods Fluids 2014, 24, 1057-1072. [CrossRef]

6. Devendiran, D.K.; Amirtham, V.A. A review on preparation, characterization, properties and applications of nanofluids. Renew. Sustain. Energy Rev. 2016, 60, 21-40. [CrossRef]

7. Kumar, V.; Tiwari, A.K.; Ghosh, S.K. Application of nanofluids in plate heat exchanger: A review. Energy Convers. Manag. 2015, 105, 1017-1036. [CrossRef]

8. Verma, S.K.; Tiwari, A.K. Progress of nanofluid application in solar collectors: A review. Energy Convers. Manag. 2015, 100, 324-346. [CrossRef]

9. Sarkar, J.; Ghosh, P.; Adil, A. A review on hybrid nanofluids: Recent research, development and applications. Renew. Sustain. Energy Rev. 2015, 43, 164-177. [CrossRef]

10. Sundar, L.S.; Sharma, K.V.; Singh, M.K.; Sousa, A.C. Hybrid nanofluids preparation, thermal properties, heat transfer and friction factor-A review. Renew. Sustain. Energy Rev. 2017, 68, 185-198. [CrossRef]

11. Sidik, N.A.; Adamu, I.M.; Jamil, M.M.; Kefayati, G.H.; Mamat, R.; Najafi, G. Recent progress on hybrid nanofluids in heat transfer applications: A comprehensive review. Int. Commun. Heat Mass Transf. 2016, 78, 68-79. [CrossRef]

12. Baytaş, A.C.; Liaqat, A.; Groşan, T.; Pop, I. Conjugate natural convection in a square porous cavity. Heat Mass Transf. 2001, 37, 467-473. [CrossRef]

13. Baytas, A.C.; Baytas, A.F.; Ingham, D.B.; Pop, I. Double diffusive natural convection in an enclosure filled with a step type porous layer: Non-Darcy flow. Int. J. Therm. Sci. 2009, 48, 665-673. [CrossRef]

14. Wu, W.; Zhang, S.; Wang, S. A novel lattice Boltzmann model for the solid-liquid phase change with the convection heat transfer in the porous media. Int. J. Heat Mass Transf. 2017, 104, 675-687. [CrossRef]

15. Chen, S.; Yang, B.; Zheng, C. A lattice Boltzmann model for heat transfer in porous media. Int. J. Heat Mass Transf. 2017, 111, 1019-1022. [CrossRef]

16. Gao, D.; Chen, Z.; Chen, L.; Zhang, D. A modified lattice Boltzmann model for conjugate heat transfer in porous media. Int. J. Heat Mass Transf. 2017, 105, 673-683. [CrossRef]

17. Miroshnichenko, I.V.; Sheremet, M.A.; Oztop, H.F.; Abu-Hamdeh, N. Natural convection of alumina-water nanofluid in an open cavity having multiple porous layers. Int. J. Heat Mass Transf. 2018, 125, 648-657. [CrossRef]

18. Dogonchi, A.S.; Sheremet, M.A.; Ganji, D.D.; Pop, I. Free convection of copper-water nanofluid in a porous gap between hot rectangular cylinder and cold circular cylinder under the effect of inclined magnetic field. J. Therm. Anal. Calorim. 2018. [CrossRef]

19. Ghalambaz, M.; Sabour, M.; Pop, I. Free convection in a square cavity filled by a porous medium saturated by a nanofluid: Viscous dissipation and radiation effects. Eng. Sci. Technol. 2016, 19, 1244-1253. [CrossRef]

20. Kasaeian, A.; Daneshazarian, R.; Mahian, O.; Kolsi, L.; Chamkha, A.J.; Wongwises, S.; Pop, I. Nanofluid flow and heat transfer in porous media: A review of the latest developments. Int. J. Heat Mass Transf. 2017, 107, 778-791. [CrossRef]

21. Izadi, M.; Hoghoughi, G.; Mohebbi, R.; Sheremet, M. Nanoparticle migration and natural convection heat transfer of $\mathrm{Cu}$-water nanofluid inside a porous undulant-wall enclosure using LTNE and two-phase model. J. Mol. Liquids 2018, 261, 357-372. [CrossRef]

22. Sheremet, M.A.; Pop, I. Effect of local heater size and position on natural convection in a tilted nanofluid porous cavity using LTNE and Buongiorno's models. J. Mol. Liquids 2018, 266, 19-28. [CrossRef] 
23. Zargartalebi, H.; Ghalambaz, M.; Sheremet, M.A.; Pop, I. Unsteady free convection in a square porous cavity saturated with nanofluid: The case of local thermal nonequilibrium and Buongiorno's mathematical models. J. Porous Media 2017, 20, 999-1016. [CrossRef]

24. Izadi, M.; Mehryan, S.A.; Sheremet, M.A. Natural convection of CuO-water micropolar nanofluids inside a porous enclosure using local thermal non-equilibrium condition. J. Taiwan Inst. Chem. Eng. 2018, 88, 89-103. [CrossRef]

25. Hashemi, H.; Namazian, Z.; Zadeh, S.M.; Mehryan, S.A. MHD natural convection of a micropolar nanofluid flowing inside a radiative porous medium under LTNE condition with an elliptical heat source. J. Mol. Liquids 2018, 271, 914-925. [CrossRef]

26. Mehryan, S.A.; Izadi, M.; Sheremet, M.A. Analysis of conjugate natural convection within a porous square enclosure occupied with micropolar nanofluid using local thermal non-equilibrium model. J. Mol. Liquids 2018, 250, 353-368. [CrossRef]

27. Zargartalebi, H.; Ghalambaz, M.; Khanafer, K.; Pop, I. Unsteady conjugate natural convection in a porous cavity boarded by two vertical finite thickness walls. Int. Commun. Heat Mass Transf. 2017, 81, 218-228. [CrossRef]

28. Mahmoudi, Y.; Maerefat, M. Analytical investigation of heat transfer enhancement in a channel partially filled with a porous material under local thermal non-equilibrium condition. Int. J. Therm. Sci. 2011, 50, 2386-2401. [CrossRef]

29. Alazmi, B.; Vafai, K. Analysis of fluid flow and heat transfer interfacial conditions between a porous medium and a fluid layer. Int. J. Heat Mass Transf. 2001, 44, 1735-1749. [CrossRef]

30. Yang, K.; Vafai, K. Analysis of heat flux bifurcation inside porous media incorporating inertial and dispersion effects-an exact solution. Int. J. Heat Mass Transf. 2011, 54, 5286-5297. [CrossRef]

31. Yang, K.; Vafai, K. Analysis of temperature gradient bifurcation in porous media-An exact solution. Int. J. Heat Mass Transf. 2010, 53, 4316-4325. [CrossRef]

32. Vafai, K.; Yang, K. A note on local thermal non-equilibrium in porous media and heat flux bifurcation phenomenon in porous media. Transp. Porous Media 2013, 96, 169-172. [CrossRef]

33. Nield, D.A. A note on local thermal non-equilibrium in porous media near boundaries and interfaces. Transp. Porous Media 2012, 95, 581-584. [CrossRef]

34. Levin, M.L.; Miller, M.A. Maxwell's “Treatise on Electricity and Magnetism”. Soviet Phys. Uspekhi 1981, 24, 904. [CrossRef]

35. Bruggeman, V.D. Berechnung verschiedener physikalischer Konstanten von heterogenen Substanzen. I. Dielektrizitätskonstanten und Leitfähigkeiten der Mischkörper aus isotropen Substanzen. Ann. Phys. 1935, 416, 636-664. [CrossRef]

36. Suresh, S.; Venkitaraj, K.P.; Selvakumar, P.; Chandrasekar, M. Synthesis of Al2O3-Cu/water hybrid nanofluids using two step method and its thermo physical properties. Colloids Surfaces A 2011, 388, 41-48. [CrossRef]

37. Lundgren, T.S. Slow flow through stationary random beds and suspensions of spheres. J. Fluid Mech. 1972, 51, 273-299. [CrossRef]

38. Brinkman, H.C. The viscosity of concentrated suspensions and solutions. J. Chem. Phys. 1952, 20, 571. [CrossRef]

39. Batchelor, G.K. The effect of Brownian motion on the bulk stress in a suspension of spherical particles. J. Fluid Mech. 1977, 83, 97-117. [CrossRef]

40. Babu, J.R.; Kumar, K.K.; Rao, S.S. State-of-art review on hybrid nanofluids. Renew. Sustain. Energy Rev. 2017, 77, 551-565. [CrossRef]

41. Mehryan, S.A.; Kashkooli, F.M.; Ghalambaz, M.; Chamkha, A.J. Free convection of hybrid Al2O3-Cu water nanofluid in a differentially heated porous cavity. Adv. Powder Technol. 2017, 28, 2295-2305. [CrossRef]

42. Kahveci, K. Buoyancy driven heat transfer of nanofluids in a tilted enclosure. J. Heat Transf. 2010, $132,062501$. [CrossRef]

43. Bourantas, G.C.; Skouras, E.D.; Loukopoulos, V.C.; Burganos, V.N. Heat transfer and natural convection of nanofluids in porous media. Eur. J. Mech. B/Fluids 2014, 43, 45-56. [CrossRef]

(C) 2019 by the authors. Licensee MDPI, Basel, Switzerland. This article is an open access article distributed under the terms and conditions of the Creative Commons Attribution (CC BY) license (http:/ / creativecommons.org/licenses/by/4.0/). 